\title{
Una reforma basada en la gestión aplicada a la Administración Pública de Brasil *
}

\section{Luiz Carlos Bresser Pereira **}

\section{La reforma de la Administración Pública}

La reforma del Estado, un tema que acaparó todas las atenciones durante la década de los 90 en todo el mundo, es una consecuencia del proceso de globalización que está teniendo lugar, en virtud del cual los Estados han visto disminuida su autonomía para crear y poner en marcha políticas y, sobre todo, de la crisis del Estado, que comienza a tomar forma en casi todo el mundo en los años 70 , aunque no termina de definirse hasta los 80. En Brasil la reforma del Estado empezó en ese momento, en medio de una gran crisis económica, cuyo punto álgido se alcanza en 1990 con una subida desmesurada de la inflación. A partir de entonces la necesidad de llevar a cabo reformas estatales pasó a ser la prioridad número uno. En ese momento se atacan directamente algunos problemas considerados vitales como el ajuste fiscal, la privatización y la apertura comercial, que ya habían sido tanteados durante los años anteriores. La reforma administrativa no se convirtió en un asunto que acaparase demasiada atención en Brasil hasta 1995, después de la elección y toma de posesión de Fernando Henrique Cardoso. En ese año la sociedad brasilena vio claramente que la reforma era una condición indispensable para la consolidación de los ajustes fiscales del Estado brasileño, por un lado, y, por otro, para que en el país pudiera existir un servicio público moderno, profesional y eficiente, al servicio de las necesidades de los ciudadanos.

El Estado estaba en crisis, por lo que había que reconstruirlo. La globalización hizo indispensable redefinir las funciones del Estado. Antes de que se integraran los mercados y los sistemas productivos mundialmente, los Estados podían plantearse el proteger sus respectivas economías de la competencia internacional como uno de sus objetivos fundamentales. Después de la globalización disminuyeron mucho las posibilidades de seguir ejerciendo esta función. La nueva función del Estado era facilitar que la economía internacional se volviese internacionalmente competitiva. La regulación y la intervención siguen siendo necesarias en la educación, en la sanidad, en la cultura, en el desarrollo tecnológico y en las inversiones en infraestructuras. Debe ser ésta una intervención que no sólo compense los desequilibrios de índole distributiva provocados por este mercado globalizado sino, sobre todo, que capacite a los agentes económicos para ser capaces de competir a nivel mundial '. En el plano económico, la diferencia entre una propuesta de reforma neoliberal y una socialdemocrática o social-liberal radica en el hecho de que el objetivo de la primera es hacer desaparecer al Estado de la economía, mientras que el de la segunda es aumentar la capacidad de gobierno del Estado. Es proporcionar al Estado medios financieros y administrativos para que pueda intervenir de forma eficaz cuando el mercado no pueda estimular la capacidad competitiva de las empresas nacionales y coordinar adecuadamente la economía.

Aunque el Estado sea, antes que nada, un reflejo de la sociedad, vamos a pensar en él aquí como sujeto, y no como objeto, como un organismo cuyo capacidad de gobierno hay que ampliar para que pueda actuar de forma más efectiva y eficaz, en beneficio de la sociedad. Los problemas de gobernabilidad no son consecuencia del "exceso de democracia", del peso excesivo de las demandas sociales, sino de la falta de un pacto político o de una coalición de clases que ocupe el centro del 
espectro político ${ }^{2}$. Nosotros partimos de que el problema politico de la gobernabilidad se identificó durante un tiempo con el retorno de la democracia y la formación del epacto democrático-reformista de 1994. que fue posible gracias al éxito del Plan Real y a la elección de Fernando Henrique Cardoso ${ }^{3}$. Este pacto no consiguió resolver definitivamente los problemas de gobernabilidad existentes en el país, pues éstos son crónicos por definición, pero proporcionó al gobierno las condiciones políticas necesarias para poder ocupar el centro político e ideológico y, después de obtener un amplio apoyo popular, poder proponer y llevar a cabo la reforma del Estado.

Por otro lado, en el ámbito social, la diferencia entre la propuesta neoliberal y el nuevo Estado Social Liberal que está surgiendo radica en el hecho de que los verdaderos neoliberales quieren que el Estado se retire también del ámbito social. Critican ferozmente la intervención del Estado, lo que en el Primer Mundo tomó la forma de welfare state, porque esta intervención, incluso en la educación y en la sanidad, acabaría siendo objeto de rent seeking (lucro) por parte de grupos especiales de intereses, formados por empresarios, grupos provenientes de la clase media, por trabajadores, que privatizan así lo que es público. Adoptando un individualismo radical y carente de realismo político, pretenden que la educación y la sanidad, por muy importantes que sean, son problemas que los individuos y las familias deben resolver y financiar por sí solos. En el intervalo de tiempo que ha pasado vemos que el resultado de dicha crítica y la respuesta socialdemocrática no es el Estado Liberal (por el que abogaba el neoconservadurismo), ni el Estado Social-Demócratà (otro nombre para designar el Welfare State), sino el Estado Social Liberal, que sigue ocupándose de proteger los derechos sociales, pero que garantiza esa protección dejando gradualmente de ejercer de forma directa las funciones relativas a la educación, la sanidad y la asistencia social, para contratar los servicios de organizaciones públicas no estatales que se encargarán de realizarlas ${ }^{4}$.

\section{Crisis y reforma}

La percepción de la naturaleza de la crisis y, a continuación, de la necesidad imperiosa de llevar a cabo reformas en el Estado surgió en Brasil de forma accidentada y contradictoria, a medida que la misma crisis empezó a tomar cuerpo. Entre 1979 y 1994 Brasil vivió un período de estancamiento de la renta per capita y de alta inflación sin precedentes en su historia. Por fin, en 1994 se estabilizaron los precios mediante el Plan Real, creándose así las condiciones necesarias para que el crecimiento pudiese continuar. La causa fundamental de dicha crisis económica fue la crisis del Estado una crisis que aún no está plenamente superada, a pesar de todas las reformas que se han llevado a cabo. Esta crisis se caracteriza por la pérdida de capacidad del Estado para coordinar el sistema económico para que éste sea un complemento del mercado. Esta coordinación económica conlleva la distribución de los recursos, la acumulación de capital y el reparto de la renta. En las economías capitalistas esa función la desempeña el mercado o el Estado. Cuando el Estado (o el mercado) entra en crisis, esa función se ve seriamente afectada.

Hay varias maneras de definir la crisis del Estado que se manifestó claramente en la década de los 80: como una crisis fiscal, como una crisis en la forma de intervención del Estado, como una crisis de la forma burocrática con la que se administra el Estado y, finalmente, como una crisis política.

La crisis política pasó por tres momentos: primero, la crisis del régimen militar, entre 1977 y 1985 — una crisis de legitimidad-; segundo, la tentativa populista (1985-1986) de volver a los años 50 - una crisis de adaptación al régimen democrático y, por último, la crisis que condujo al enjuiciamiento de Fernándo Collor de Mello- una crisis moral. La crisis fiscal o financiera se caracterizó por la pérdida del crédito público o por el ahorro público negativo. La crisis del modo de intervención, acelerada por el proceso de globalización de la economía mundial, se caracterizó por el agotamiento del modelo proteccionista de sustituir las importaciones por la producción interna, que consiguió fomentar la industrialización de los años 30 a los 50 , pero que dejó de hacerlo a partir de los años 60 , haciéndose patente en la falta de competitividad que mostraba una parte importante de las empresas brasileñas. La crisis se tradujo en el intento fracasado de crear en Brasil un Estado del Bienestar que se aproximara a los modelos socialdemocráticos europeos. Finalmente, la forma burocrática de administración del Estado entró en una profunda crisis después de la Constitución de 1988, antes incluso de que la misma administración pública burocrática se pudiese instaurar en el país.

La crisis del modelo de administración pública burocrático, que se había introducido en el país en los años 30, durante el gobierno Vargas, empezó ya durante el régimen militar, debido a la incapacidad de éste para erradicar las prácticas patrimonialistas o clientelistas de la administración. El régimen militar pudo crear organismos burocráticos aislados, que siguieron, sin embargo, coexistiendo con el clientelismo y el corporativismo (NunEs, 1984). En vez de consolidar una democracia profesional en el país, mediante una redefinición de los profesiones y de un proceso sistemático de convocatoria de oposiciones para los puestos elevados de la administración, el régimen militar prefirió tomar el camino más corto y encontrar a sus administradores a través de las empresas estatales '. Esta estrategia oportunista del régimen militar, que decidió optar por la salida más fácil para contratar a los altos cargos de la administración a través de las empresas, hizo inviable la construcción en el país de una burocracia civil fuerte, según las pautas propuestas por la reforma 
de 1936. Mientras tanto, la crisis se agravó con la Constitución de 1988, al pasarse al otro extremo, pasando la administración pública brasileña a sufrir de la enfermedad contraria: el anquilosamiento burocrático extremo. Las consecuencias de la supervivencia del patrimonialismo y del anquilosamiento burocrático, muchas veces perversamente combinados, van a ser los causantes del elevado coste y la baja calidad de la administración pública brasileña ${ }^{6}$.

La respuesta que la sociedad brasileña dio a los cuatro aspectos de la crisis del Estado no fue equilibrada y surgió en diferentes momentos. La primera fue la respuesta a la crisis política: en 1985 el país completó su transición democrática, consolidándola en 1988 con la aprobación de la nueva Constitución. En lo que se refiere ya a los otros tres aspectos - la crisis fiscal, el agotamiento del modo de intervención, y la creciente ineficacia del aparato estatal- el nuevo régimen instaurado en el país en 1985 fue de poca ayuda ${ }^{7}$. Por el contrario: en un primer momento agravó los problemas, convirtiéndose en un ejemplo clásico de movimiento que provoca el efecto contrario al deseado. En lo que se refiere a la crisis fiscal y al modo de intervención del Estado, las fuerzas políticas victoriosas tenían como parámetro de medida el desarrollo populista de los años 50 y en lo relativo a la administración pública, la visión burocrática de los años 30.

\section{De la administración}

\section{burocrática a la administración basada en la gestión}

La administración burocrática clásica, que se basa en los principios de la administración del ejército prusiano, se implantó en los principales países europeos a finales del siglo pasado, en los Estados Unidos a principios de este siglo y en Brasil en 1936. Los fundamentos de este modelo son un cuerpo profesional de funcionarios, ascensos basados en los méritos y en el tiempo de servicio y en una definición legal rígida de objetivos y de los medios para alcanzarlos. En el caso de Brasil, aunque se haya dado importancia a ciertos instrumentos en la época, como la institución del sistema de oposiciones y la formación sistemática, no se llegó a adoptar de una forma sólida una política de recursos humanos que se adecuase a las necesidades del Estado. A pesar de encontrarse en proceso de transformación, el patrimonialismo (para luchar contra el cual se había instalado la administración pública burocrática) mantenía un poder propio en el marco político brasileño. La expresión local de patrimonialismo -el coronelismo- dio origen al clientelismo y al fisiologismo, y continuaba filtrándose en la administración del Estado brasileño.

La administración pública burocrática se adoptó para sustituir a la administración patrimonialista, que caracterizó a las monarquías absolutas, en la que se confundían el patrimonio público y el privado. El nepotismo y el empleadismo, por no decir la corrupción, estaban a la orden del día. Con la aparición del capitalismo y de la democracia surgió la necesidad de crear un tipo de administración en cuya base no sólo existiera una clara distinción entre lo público y lo privado, sino también una separación entre el político y el administrador público. De esa manera empieza a cobrar forma la administración burocrática moderna, racional-legal (utilizando el término acuñado por $\mathrm{WE}$ BER). Surge la organización burocrática basada en la centralización de las decisiones, en la jerarquía traducida en la unidad de mando, en la estructura piramidal del poder, en las rutinas rígidas, en el control paso por paso de los procesos administrativos, en una burocracia estatal formada por administradores profesionales escogidos y formados para desempeñar especialmente esa función, que en forma neutra son equivalentes a los políticos. Max WEBER (1922) definió y describió de forma genial este tipo de administración a principios de este siglo.

Como la administración pública burocrática nació como una forma de luchar contra el patrimonialismo y se implantó en el siglo XIX, en el momento en que la democracia daba sus primeros pasos, se comprende que desconfiase de todo y de todos -de los políticos, de los empleados, y de los ciudadanos-. Se consideraba necesario que existieran controles rigurosos y controles de comportamiento del sistema. Siempre que era posible se preferían las leyes, reglamentos y prácticas de procedimiento a la toma de decisiones. La administración pública basada en la gestión, por su lado, y sin pecar de ingenua, ya parte del presupuesto de que se ha alcanzado ya un nivel cultural y políico en el que el patrimonialismo está condenado, en el que el burocratismo queda excluido porque es ineficaz y en el que es posible desarrollar estrategias administrativas que se basen en delegar una parte importante de la autoridad para pedir resultados a posteriori.

Poco a poco se fue esbozando el encuadre de la nueva administración pública o administración pública basada en la gestión en varios países, principalmente en Inglaterra, Nueva Zelanda y Australia: (1) descentralización desde el punto de vista político, lo que conlleva la transferencia de recursos y atribuciones a las instancias políticas regionales y locales; (2) descentralización administrativa, delegándose autoridad en los administradores públicos convertidos en gestores cada vez con mayor autonomía; (3) organizaciones con pocos niveles jerárquicos, y no piramidales; (4) organizaciones flexibles en contraposición a las unitarias y monolíticas, en las que se den las ideas de multiplicidad, competencia regulada y conflicto; (5) presupuesto de confianza limitada y no de desconfianza total; (6) definición de los objetivos 
que deben alcanzar las unidades centralizadas como indicadores de rendimiento, cuantitativos siempre que sea posible, que constituirán el núcleo del contrato de gestión entre el ministro y el responsable del órgano que se está transformando en agencia; (7) control por resultados, a posteriori, en contraposición al control rígido, paso por paso, que se ejercía en los procesos administrativos; y (8) una administración con la atención centrada en atender al ciudadano, en lugar de en ella misma.

Ampliando lo dicho, la administración pública basada en la gestión se apoya en una concepción del Estado y de la sociedad democrática y plural, mientras que en la administración pública burocrática la costumbre es la centralización y el autoritarismo. A fin de cuentas el liberalismo del siglo XIX, en el que se fraguó la forma burocrática de administración pública, era un régimen político de transición entre el autoritarismo y la democracia. Mientras que la administración pública burocrática cree en una racionalidad absoluta, que la burocracia está encargada de garantizar, la administración pública basada en la gestión piensa en la sociedad como en un lugar de conflicto, cooperación e inseguridad, en el que los ciudadanos defienden sus intereses y afirman sus posiciones ideológicas, que en última instancia se expresan en la administración pública. Formulado en estos términos, el problema no sería alcanzar la racionalidad perfecta, sino idear instituciones y prácticas administrativas suficientemente abiertas y transparentes como para garantizar que el Estado se ocupe de forma razonable del interés colectivo en la producción de bienes públicos o "casi públicos.

\section{Las dos reformas administrativas}

En Brasil la idea de una administración pública basada en la gestión ya es antigua. En 1936 se introdujeron en el país los principios de la administración burocrática clásica a través de la creación del DASP - Departamento Administrativo del Servicio Público- ${ }^{8}$. La creación del DASP constituye la primera reforma administrativa realizada en el país ${ }^{9}$. Entretanto, encontramos ya en 1938 la primera señal de la aparición de la administración pública basada en la gestión: la creación del primer gobierno autónomo. Surgió entonces la idea de que los servicios públicos con funciones ejecutivas y no de elaboración de políticas -administración directan- deberían descentralizarse y dejar de regirse por los requisitos burocráticos de la *administración directa. o central.

La primera tentativa de reformar la administración pública brasileña, pasando al sistema de gestión, iba a producirse a finales de los años 60, con el Decreto Ley 200, de 1967, promovido por Amaral Peixoto a sugerencia de Hélio Beltrão, quien se convertiría en pionero de las nuevas ideas en Brasil ${ }^{10}$. La reforma iniciada por el Decreto Ley 200 constituyó un intento de superar la rigidez burocrática, pudiendo considerarse como la primera fase de la administración basada en la gestión en Brasil. El punto en el que se hizo mayor hincapié fue en llegar a una descentralización mediante la autonomía de la administración indirecta, partiendo del presupuesto de que la administración directa era más rígida y la administración descentralizada más eficaz ". El Decreto Ley apoyó la transferencia de las actividades destinadas a la producción de bienes y servicios a los gobiernos autónomos, fundaciones, empresas públicas y sociedades de economía mixta, racionalizando y ratificando una situación que ya se vislumbraba en la práctica. Se instituyeron como principios de racionalidad administrativa la planificación y el presupuesto, la descentralización y el control de los resultados. En las instancias descentralizadas se utilizaron trabajadores celetistas (con contrato de acuerdo con la CLT, Consolidación de las Leyes del Trabajo), sometidos al régimen privado de contratación. Fue el momento del gran boom de las empresas estatales y de las fundaciones. Mediante la flexibilización de su administración se pretendía conseguir una mayor eficacia en los servicios y actividades económicas del Estado, a la vez que se fortalecía la alianza política entre las altas esferas de la tecnoburocracia estatal, civil y militar, y la clase empresarial ${ }^{12}$.

El Decreto Ley 200 tuvo dos consecuencias inesperadas e indeseables. Por un lado, al permitir la contratación de trabajadores sin oposiciones, facilitó la supervivencia de prácticas patrimonialistas y fisiológicas (en las que prevalece por encima de todo la voluntad del que las lleva a cabo). Por otro lado, al no ocuparse de realizar cambios en el ámbito de la administración directa o central, que se veía despectivamente como •burocrática. o rígida, dejó de convocar oposiciones y de incentivar las trayectorias profesionales de altos administradores. De esta manera, el núcleo estratégico del Estado se debilitó indebidamente mediante una estrategia oportunista del régimen militar que, en lugar de preocuparse de formar administradores públicos de alto nivel seleccionados a través de oposiciones, prefirió contratar a los que ocuparían los puestos más altos de la administración a través de empresas estatales ${ }^{13}$

Así fue cómo la reforma administrativa contenida en el Decreto Ley 200 se quedó a la mitad y fracasó. La crisis política del régimen militar, que comenzó ya a mediados de los años 70 , agravó aún más la situación de la administración pública, en la medida en que se identificó a la burocracia estatal con el sistema autoritario en pleno proceso de desintegración.

\section{La vuelta a los años 50 y 30}

La transición democrática que tiene lugar con la elección de Tancredo Neves y la toma de posesión de José Sarney, en marzo de 1985, no va a traer consigo, sin embargo, buenas pers- 
pectivas para una reforma del aparato estatal. Por el contrario, en el ámbito administrativo se va a traducir en una vuelta a los ideales burocráticos de los años $30 \mathrm{y}$, en el político, en un intento de volver al populismo de los años 50 . Los dos partidos que controlaron la transición eran partidos democráticos, pero populistas. No tenían, como tampoco tenía la sociedad brasileña, noción de la gravedad de la crisis que el país estaba atravesando. Además, se vivía una especie de euforia democrático-populista. En las mentes rondaba la idea de que era posible volver a los años dorados de la democracia y del desarrollo brasileño, que fueron los años 50 .

El capítulo dedicado a la administración pública que se incluye en la Constitución de 1988 va a ser el resultado de todas esas fuerzas contradictorias. Por un lado, es una reacción al populismo y al fisiologismo que se recrudeció con el advenimiento de la democracia ${ }^{14}$. Por esta razón, la Constitución va a consagrar los principios de una administración pública muy centralizada, jerárquica y rígida, en la que se da total prioridad a la administración directa en lugar de a la indirecta. La Constitución de 1988 ignoró completamente las nuevas orientaciones de la administración pública. Los constituyentes, y de una forma más amplia, la sociedad brasileña demostraron en ese momento una increíble incapacidad para comprender un enfoque nuevo. Para ellos lo único comprensible era que la administración burocrática clásica, que se había empezado a introducir en los años 30 , no se había implantado completamente. Vieron que el Estado había adoptado estrategias descentralizadoras - los gobiemos autónomos y las fundaciones públicas- que no se encuadraban en el modelo burocrático-profesional clásico. Notaron que esa administración había dejado un cierto espacio libre en el que se había colado el clientelismo, sobre todo a nivel de estados y municipios un clientelismo que se había fortalecido después de la redemocratización. No comprendieron que las formas más descentralizadas y flexibles de la administración, que el Decreto Ley 200 había servido para afianzar, eran una respuesta a la necesidad de que el Estado administrase de forma eficaz las empresas y los servicios sociales. $Y$ decidieron completar primero la revolución burocrática para pensar más tarde en los principios de la administración pública moderna.

Partiendo de ese punto de vista decidieron: (1) tomando como punto de partida la instauración de un rrégimen jurídico único" para todos los funcionarios públicos civiles de la administración pública directa y de los ayuntamientos y fundaciones, tratar de la misma manera a limpiadores y jueces, a profesores y a agentes de policía, a porteros y a altos cargos de la administración pública que ejercen el poder del Estado; (2) mediante una estabilidad rígida hacer imposible que el puesto de trabajo de los funcionarios incompetentes o innecesarios reporte algún beneficio al bien común, olvidando que esta institución se creó para defender al Estado y no a sus funcionarios; (3) mediante un sistema de oposiciones aún más rígido, hacer inviable que los funcionarios ya existentes tuvieran acceso a nuevas plazas; (4) haciendo extensivas las nuevas reglas a toda la administración pública, eliminar toda la autonomia de los gobiernos autónomos y las fundaciones públicas; (5) mediante una serie de dispositivos, crear un sistema de evidente privilegio en la jubilación de los funcionarios públicos y para sus pensionistas.

De esta manera, y en contradicción con su espíritu burocrático racional-legal, la Constitución de 1988 permitió que se consolidasen o creasen varios privilegios. Privilegios que fueron al mismo tiempo el tributo que se pagó al patrimonialismo todavía presente en la sociedad brasileña, y una consecuencia del corporativismo al que la apertura democrática insufló nuevas fuerzas, llevando a todos los agentes sociales a defender sus intereses particulares como si fuesen intereses generales. El privilegio más grave fue el establecimiento de un sistema de jubilación con sueldos íntegros, en el que no contaba para nada el tiempo en el que se hubiera prestado servicio directamente al Estado. Este hecho, unido a la entrada de jubilaciones especiales, que permitian a los funcionarios jubilarse muy anticipadamente, alrededor de los 50 años, y, en el caso de los profesores universitarios, acumular jubilaciones, aumentó violentamente el coste del sistema estatal de cobertura social, lo que representó una pesada carga fiscal para la sociedad ${ }^{15}$. Un segundo privilegio fue el haber permitido que más de 400.000 funcionarios celetistas se convirtiesen de golpe en funcionarios de carrera, con puesto fijo y jubilación íntegra ${ }^{16}$.

El retroceso burocrático de 1988 no se puede atribuir a un supuesto fracaso de la descentralización y de la flexibilización de la administración pública ocasionada en última instancia por el Decreto Ley 200. Aunque se hayan cometido algunos abusos en su nombre, ya sea por una excesiva autonomía concedida a las empresas estatales o por el uso patrimonialista hecho de los ayuntamientos y fundaciones (donde no se exigía un proceso selectivo público a la hora de admitir personal), no es correcto afirmar que tales distorsiones puedan considerarse como causantes de este fenómeno. La verdad es que el retroceso fue el resultado, en primer lugar, de una visión equivocada de las fuerzas democráticas que derrocaron al régimen militar, acerca de la naturaleza de la administración pública vigente entonces. En la medida en que, en Brasil, la transición democrática tuvo lugar en medio de la crisis del Estado, esta última fue considerada, equivocadamente, por las fuerzas democráticas como resultado, entre otros, del proceso de descentralización que el régimen militar había intentado implantar. En segundo lugar, fue consecuencia de la alianza política que dichas fuerzas se vieron obligadas a sellar durante el proceso de transición democrática con grupos corporativos y clientelistas, en el momento en el que el populismo económico se convertía en la tendencia dominante. En tercer lugar, resultó del resentimiento de la vieja burocracia 
por la forma en que el régimen militar trató a la administración central: era el momento de restablecer la fuerza del centro y la pureza del sistema burocrático. Esta visión burocrática se concentró en la antigua SAF, que se convirtió en el centro de la reacción burocrática del país no sólo contra una administración pública moderna, sino también a favor de los intereses corporativistas del funcionalismo ${ }^{17}$. Para finalizar, un cuarto factor aparece relacionado con la campaña a favor de la desestatización que corrió paralela a toda la transición democrática. Las empresas estatales se vieron como demasiado poderosas, lo que llevó a los constituyentes a aumentar los controles burocráticos aplicados a ellas, que habían conseguido mucha autonomía gracias al Decreto Ley 200.

A modo de sintesis, se puede afirmar que el retroceso burocrático de la Constitución de 1988 fue una reacción al clientelismo dominante en el país durante aquellos años, aunque también fue una afirmación de los privilegios corporativistas y patrimonialistas incompatibles con el ethos burocrático. Además, fue una consecuencia de la actitud defensiva de la alta burocracia que, sintiéndose acosada e injustamente acusada, se defendió irracionalmente.

Todas estas circunstancias contribuyeron al desprestigio de la administración pública brasileña, a pesar del hecho de que los administradores públicos brasileños sean mayoritariamente competentes, honrados y con conciencia pública. Estas cualidades, que vienen demostrando desde los años 30 , cuando se implantó en Brasil la administración pública profesional, fueron un factor que intervino de forma decisiva en la función estratégica que el Estado desempeñó en el desarrrollo de la economía brasileña. La implantación de la industria de base en los años 40 y 50 , el ajuste de los años 60 , el desarrollo de infraestructuras y la instalación de industrias de bienes de capital en los años 70 , el nuevo ajuste y la reforma financiera de los años 80 y la liberalización comercial de los 90 no habrían sido posibles sin el buen hacer profesional y la conciencia pública de la burocracia brasileña ${ }^{18}$.

\section{Los salarios y la nómina}

Durante el período autoritario no existió una política salarial para los funcionarios públicos federales, y esa ausencia no fue corregida a la vuelta a la democracia. Las distorsiones salariales, que eran ya graves, no hicieron más que agravarse, mientras que el total de gastos, que aumentó durante el gobierno Sarney, fue drásticamente reducido por el gobierno Collor, mediante una disminución importante de los salarios medios reales. Durante el gobierno Itamar se volvió al nivel anterior de salarios, al tiempo que el total de gastos unidos a personal crece de forma explosiva. Según demuestra la Tabla 1, los salarios, que en- tre 1989 y 1992 se habian reducido a la mitad, llegan en 1995 a un nivel más elevado que el tope anterior (1990). A partir de finales de 1992 y con ayuda de un programa de :isonomía salarialn, el gobiemo intentó corregir las profundas irregularidades existentes en la remuneración de los funcionarios que se habían acumulado desde la segunda mital de la década de los 80 . Se llevaron a cabo algunas correcciones, pero el resultado más destacable fue un aumento sin precedentes de los gastos de personal, que alcanzaron un tope histórico en 1995, sin que se eliminasen las distorsiones.

\begin{tabular}{|ccc|}
\hline \multicolumn{3}{c|}{ Tabla 1 } \\
Remuneración media real de los funcionarios \\
del Ejecutivo (1989=100)
\end{tabular}

- Nota: El índice ponderado se calculó partiendo del indice de las profesiones más importan. tes ponderado por el número de personas penenecientes a cada profesión. Se ha resaltado el indice del nivel 1 superior del PCC — Plano de Clasificación de Cargos-, porque ésa es la profesion más representativa del funcionariado brasileño.

* Cálculo basado en datos anteriores a marzo de 1997

Fuente: MARE - Ministerio de la Administración Federal y de la Reforma del Estado-

El aumento de las remuneraciones que se produjo durante el gobiemo Itamar, sumado a algunos aumentos adicionales realizados durante los tres primeros meses del gobierno de Fernando Henrique provocaron un fuerte aumento de los salarios medios reales, y un crecimiento desmesurado de los gastos relativos a personal en el gobierno federal. En la Tabla 2 se presentan los datos más importanates relativos al gasto global. En 1995 el gasto de personal alcanzó, en reales deflacionados, un punto máximo absoluto: 44.000 millones de reales (1 real $=150$ pts. aprox.), lo que supone un aumento de un $30 \%$ real de 1994 a 1995. Ese porcentaje es semejante al aumento del salario medio real que tiene lugar en el mismo período de tiempo. Sin embargo, en cuanto a la participación de 
las nóminas en el PIB, el punto máximo alcanzado sigue siendo el correspondiente a 1990, como resultado del aumento de sueldos que el gobierno que salía entonces concedió a los funcionarios federales. Hasta 1996 no fue posible controlar los sueldos y la nómina del gobierno, como se puede apreciar en las tablas 1 y 2.

\begin{tabular}{|c|c|c|c|}
\hline \multirow[b]{3}{*}{1987} & $\begin{array}{r}\text { Table } \\
\text { astos de personal fed }\end{array}$ & 2 & ar) $*$ \\
\hline & en miles de millones de $\mathrm{R} \$$ & Indice $(1987=100)$ & $\%$ del PIB * \\
\hline & 18,9 & 100,0 & 3,18 \\
\hline 1988 & 23,2 & 122,7 & 3,91 \\
\hline 1989 & 28,7 & 151,6 & 4,68 \\
\hline 1990 & 33,1 & 115,3 & 5,63 \\
\hline 1991 & 27,1 & 143,3 & 4,6 \\
\hline 1992 & 22,1 & 116,7 & 3,78 \\
\hline 1993 & 29,8 & 157,7 & 4,9 \\
\hline 1994 & 34,4 & 181,9 & 5,35 \\
\hline 1995 & 44,7 & 236,3 & 6,68 \\
\hline 1996 & 43,0 & 227,0 & 6,22 \\
\hline 1997 & 42,5 & 224,4 & \\
\hline
\end{tabular}

- Indice deflactado por el IGP-DV/FGV. Valores obtenidos mediante el criterio de competencia

- Sobre la cantidad calculada para 1997.

*. Cantidad acumulada entre marzo y febrero de 1997.

Los aumentos salariales realizados durante el gobierno Itamar no lograron reducir las distorsiones salariales existentes dentro del funcionariado federal. Es posible evaluar dichas distorsiones desde dos puntos de vista: por un lado, tenemos los desequilibrios que aparecen al comparar los sueldos de los funcionarios con el mercado de trabajo privado y, por otro lado, los desequilibrios internos, pues se observan sueldos muy altos en algunos sectores y en otros, sueldos muy bajos.

Existe la creencia generalizada por todo el país de que la remuneración que reciben los funcionarios es baja. Esto no es así. En algunos sectores es baja y en otros es alta. La Tabla 3 está elaborada comparando los sueldos del sector público y del sector privado, comparando los sueldos correspondientes a puestos con atribuciones semejantes en ambos sectores. Los resultados muestran que mientras los ejecutivos y profesionales superiores obtienen una remuneración más elevada en el sector privado, los trabajadores menos cualificados del sector público (como los que trabajan en actividades auxiliares como administración, mecanografía, almacenamiento, mantenimiento, instalación, seguridad, portería, limpieza y contratas de restaurantes y cafeterías, entre otros) reciben sueldos bastante más altos que sus compañeros del sector privado. De esta manera, el sector público comige el fuerte desnivel existente entre los altos sueldos y los bajos salarios del sector privado, un desnivel que explica en buena parte el alto índice de concentración de la renta en el país, pero que, para ello, crea otra distorsión: la imposibilidad de comunicación entre los mercados de trabajo público y privado.

Por otro lado, dentro del funcionariado federal, encontramos también enormes disparidades entre las remuneraciones recibidas dentro del Estado: funcionarios con cualificaciones muy parecidas que realizan tareas muy parecidas reciben, sin embargo, remuneraciones muy diferentes. El origen de estas distorsiones internas se remonta al régimen militar, cuando el funcionariado fue relegado a un segundo plano y se pasó a emplear a la burocracia del Estado a través de las empresas estatales. la consecuencia de esta decisión fue una fuerte disminución de los sueldos de los funcionarios fijos que se refleja hasta hoy en la baja remuneración de los participantes en el Plan de Clasificación de Cargos, que entonces se intentaba ver como el sistema universal de promoción y remuneración de los funcionarios federales.

Para salir de esa situación (o del PCC) se adoptaron dos tipos de estrategias: el poder judicial, el ministerio público y el poder legislativo, dotados de gran autonomía desde el punto de vista administrativo desde 1988, trataron de aumentar sus sueldos por su cuenta, sin contar con el poder ejecutivo. Por otro lado, dentro del ejecutivo, las categorías profesionales tradicionalmente más poderosas - los procuradores, los comisarios de policía, los diplomáticos, los auditores fiscales-y las nuevas profesiones de administradores-economistas creadas después de la apertura democrática - los analistas del tesoro y del presupuesto y los gestores gubernamentales- empezaron a recibir "gratificaciones por productividad, lo que, en realidad, no era otra cosa que una estrategia de aumento de suelo. Dado su carácter ad boc, la aplicación de estas dos estrategias perfectamente comprensibles y hasta cierto punto necesarias, se saldaron con un crecimiento de las distorsiones existentes en el sistema de remuneraciones de los funcionarios del Estado.

Por último, las distorsiones del sistema federal de remuneraciones tienen una tercera causa: los fallos de la ley. Estos fallos se perciben principalmente en dos mecanismos: la posibilidad de "añadir ventajas temporales" como "quinquenios", y la posibilidad de que funcionarios, en activo o no, acumulen cargos acompañados de sus respectivas ventajas. Esta suma de ventajas temporales y las acumulaciones de cargos, hábilmente manipuladas, permitieron que un número creciente de trabajadores co- 
Tabla 3

Sueldos medios: sector público y privado (reales de mayo de 1995)

\begin{tabular}{|lccc|} 
& Sueldo medio del sector privado & Sueldo medio del sector público & Diferencia público/privado \\
\cline { 2 - 4 } & 7.080 & 5.736 & $-19 \%$ \\
Puestos Ejecutivos & 1.899 & 1.814 & $-5 \%$ \\
Puestos de Grado Superio & 926 & 899 & $-3 \%$ \\
Puesto de Grado Técrico/Medio & 437 & 635 & $45 \%$ \\
\hline
\end{tabular}

Fuente: MARE (1995): SLAPE (Sistema Integrado de Administración de Personal).

menzase a ganar sueldos elevados, por lo que apareció la expresión "marajás" para referirse a ellos. La Constitución de 1988 intentó solucionar el problema mediante la creación de un atecho de sueldos", una cantidad que indicaba el sueldo máximo que podía percibirse en cada uno de los poderes (ministros de Estado, diputados federales y senadores y ministros del Supremo Tribunal Federal), pero la interpretación que de él hizo el Supremo Tribunal Federal, que excluyó de esa cantidad las ventajas personales, le restó toda su eficacia. En 1996 los gobernantes esperaban que la enmienda de la administración pública lograse definir el techo con claridad, para terminar de una vez por todas con los marajás.

Como ya hemos visto en la Tabla 2, los aumentos de sueldo concedidos durante el gobierno Itamar ocasionaron una enorme subida en la nómina del gobierno federal. La nómina casi dobló su valor en términos reales: de 22.100 millones de reales en 1992, subió a 44.700 millones en 1995. Hasta 1996 no se consiguió controlar la nómina, que disminuyó a 43.000 millones de reales.

Este crecimiento de la nómina no se debió al aumento del número de trabajadores. Dada la necesidad de realizar ajustes fiscales, que se hizo patente a partir de 1987, y dado el elevado coste que suponía la contratación de nuevos funcionarios, desaparecieron las oposiciones casi totalmente a partir de 1988, por lo que disminuyó el número total de funcionarios. La verdad es que, tal como se puede observar en la Tabla 4, el número de funcionarios en activo, que llegó a alcanzar los 713.000 en 1989, descendió a 567.000 en 1995 y a 535.000 en 1997. Si se tiene en cuenta a los trabajadores de las empresas estatales, la caída fue aún mayor, debido al hecho anadido de las privatizaciones.

La explicación de este incremento del importe de la nómina se encuentra en el aumento de los sueldos a partir de 1993, y en el coste creciente de los funcionarios inactivos. Las elevadas pensiones de jubilación, casi un $20 \%$ más que el último sueldo correspondiente a la actividad, cuando en otros países varían en torno al $70 \%$ de la última cantidad percibida, unido al hecho de que los funcionarios pudieran jubilarse muy pronto, condujo a un desbordamiento del coste que para el Estado representaban los inactivos. Los inactivos y pensionistas, que ya representaban el 30\% del coste de la nómina de personal en 1991/1993, pasaron a representar el $40 \%$ en 1995 .

Por otro lado, hay que tener en cuenta que Brasil posee probablemente el sistema de cobertura social más generoso del mundo. Mientras que en los demás países la jubilación tiene lugar a los 60, o más a menudo, a los 65 años, en Brasil los trabajadores se jubilan por término medio, a los 53 años, subiendo a los 56 años si no se contabilizan las jubilaciones proporcionales (que dependen del tiempo trabajado). En otros paises la proporción relativa al último salario con la que el funcionario se jubila oscila entre el 50 y el $75 \%$, mientras que en Brasil era hasta hace poco del 120\%. Los trabajadores rurales, que son los más pobres, se jubilan por término medio a los 63 años con un salario mínimo. Los trabajadores urbanos se jubilan un poco antes y recibiendo una pensión mayor, aunque muy lejana de las jubilaciones del sector público.

Observando la Tabla 5 es posible hacerse una idea del privilegio que constituye el actual sistema de jubilación del sector público si se compara con el sector privado. El importe que suman las jubilaciones de los funcionarios del legislativo es 21,7 veces mayor que las jubilaciones de los beneficiarios del INSS. En el caso del judicial, 20,4 veces y, del ejecutivo, 8,25 veces. Como el número de funcionarios de los dos primeros poderes es pequeño, la media general debe rondar las 8 veces. Es cierto que desde 1993 los funcionarios contribuyen a su sistema de cobertura social, por término medio con un $11 \%$ de su salario, sin límite de remuneración. En el caso del INSS, por el contrario, el límite de la contribución y del beneficio está fijado en 10 salarios mínimos. Por esta razón, los funcionarios contribuyen, por término medio, con más que los trabajadores del sector privado. Sin embargo, los cálculos realizados muestran que su con- 
Tabla 4́

Evolución del número de funcionarios de la Unión

\begin{tabular}{|lll|} 
& Ruacioparios Civiles Fijos * & Uniön * \\
\cline { 2 - 3 } 1988 & 705.548 & 1.442 .657 \\
1989 & 712.740 & 1.488 .608 \\
1990 & 628.305 & 1.338 .155 \\
1991 & 598.375 & 1.266 .495 \\
1992 & 620.870 & 1.284 .474 \\
1993 & 592.898 & 1.258 .181 \\
1994 & 583.020 & 1.197 .460 \\
1995 & 567.689 & 1.222 .236 \\
1996 & 563.708 & 1.098 .727 \\
$1997 * *$ & 535.431 & \\
\hline
\end{tabular}

- Civiles de la administración directa (poder ejecutivo), ayuntamientos y fundaciones.

- Aparte de los fijos, incluye a los trabajadores de las empresas públicas.

* Datos de marzo

Fuente: Ministerio de la Administración Federal y de la Reforma del Estado.

tribucion media es sólo 3,4 veces superior a la contribución media que se hace al INSS, mientras que el beneficio es 8 veces más elevado.

\begin{tabular}{|lcc|}
\hline \multicolumn{3}{|c|}{ Tabla 5 } \\
& \multicolumn{2}{c|}{ Jubilaciones medias Unión/INSS } \\
\hline & En salarios minimos & Mutuplicado por \\
\hline INSS & 1,7 & 1,0 \\
Ejecutivo & 14,0 & 8,25 \\
Legisslativo & 36,8 & 21,7 \\
Judicial & 34,7 & 20,4 \\
\hline
\end{tabular}

Fuente: Ministerio de la Administración Federal y de la Reforma del Estado y Ministerio de la Cobertura Social.

\section{Objetivos}

A partir de 1995; con el gobiemo de Fernando Henrique, surge una nueva oportunidad para la reforma del Estado en general y, más en concreto, del aparato estatal y de su personal. Los objetivos de esta reforma van a ser: a conto plazo, facilitar el ajuste fiscal, especialmente en los estados de la Federación y en los municipios, donde existe un problema claro de exceso de mandos, y a medio plazo, hacer la administración pública más eficiente y moderna, centrándolo en la atención a los ciudadanos.

Los ajustes fiscales se realizarian principalmente mediante la aplicación de varias medidas: a) destitución de trabajadores debido al exceso de mandos; b) fijación de la remuneración máxima permitida para los funcionarios; y c) modificación del sistema de jubilaciones: se aumenta el tiempo exigido de ejercicio en puesto de funcionario, la edad mínima de jubilación, se exige un tiempo mínimo de estancia en el puesto de funcionario y se modifica la cantidad percibida en concepto de jubilación para hacerla proporcional a la contribución realizada. Las tres medidas van a exigir cambios constitucionales. Una alternativa al despido por exceso de mandos, que probablemente se utilizará mucho, va a ser el desarrollo de sistemas de destitución o desvinculación voluntaria. En estos sistemas los administradores escogen la población de funcionarios susceptible de ser despedida y les proponen que una parte de ellos se despida voluntariamente a cambio de una indemnización o de formación para poder incorporarse al mercado privado. Frente a la inminente posibilidad de despido y las ventajas que se ofrecen a aquellos que se desvinculen voluntariamente, un número importante de funcionarios optará por esta vía ${ }^{19}$.

La modernización o el aumento de eficacia de la administración pública va a ser el resultado a medio plazo de un complejo proyecto de reforma, mediante el cual se intentará en un solo trazo fortalecer la administración pública directa o ^núcleo estratégico del Estadon y descentralizar la administración pública creando agencias ejecutivas" y organizaciones sociales" controladas por contratos de gestión. En este sentido, no se puede calificar a la reforma propuesta de centralizadora, como fue la de 1936, ni de descentralizadora, como pretendió ser la de 1967 . $\mathrm{Ni}$, de nuevo, centralizadora, como fue la contrarreforma contenida en la Constitución de 1988. En otras palabras, la propuesta no era continuar inmersos en el proceso cíclico que había caracterizado a la administración pública brasileña, alternando períodos de centralización y descentralización, sino fortalecer al mismo tiempo la calidad administrativa del centro y la autonomía de las agencias ejecutivas y de las organizaciones sociales. El nexo de unión entre los dos sistemas será el contrato de gestión, que el núcleo estratégico deberá aprender a definir y a controlar, y sus agencias y organizaciones sociales, a poner en práctica ${ }^{20}$. 


\section{Sectores del Estado}

La propuesta de reforma del aparato estatal parte del hecho de que existen cuatro sectores dentro del Estado: (1) el núcleo estratégico del Estado, (2) las actividades exclusivas del Estado, (3) los servicios no exclusivos o competitivos, y (4) la producción de bienes y servicios para el mercado.

En el núcleo estratégico se elaboran las leyes y políticas públicas. Es un sector relativamente pequeño, formado en Brasil, a nivel federal, por el Presidente de la República, por los ministros de Estado y por la cúpula de los ministerios, que se responsabilizan de elaborar las políticas públicas, por los tribunales federales encabezados por el Supremo Tribunal Federal y por el Ministerio Público o Fiscalía del Estado, y por los miembros del Congreso. Existen correspondientes núcleos estratégicos a nivel de estados y a nivel municipal.

Las actividades exclusivas del Estado son aquéllas en las que se ejerce el "poder de Estado", o sea, el poder de legislar y cobrar impuestos. Abarca la policía, las fuerzas armadas, los órga- nos de fiscalización y reglamentación, y los órganos responsables de la transferencia de recursos a las áreas sociales y científicas, como el Sistema Unificado de Salud, el sistema de ayuda al desempleo, etc.

Los servicios no exclusivos o competitivos del Estado son aquellos que, aunque no impliquen poder de Estado, éste realiza y/o subvenciona por considerarlos de gran relevancia para la defensa de los derechos humanos, o porque implican a economías externas, y que no pueden recibir una retribución adecuada en el mercado mediante una retribución por los servicios. De este sector formarian parte los servicios sociales y científicos, como escuelas, universidades, hospitales, museos, centros de investigación, instituciones de asistencia social, etc.

Por último, el Estado produce bienes y servicios a través de las empresas de economía mixta, que operan en sectores de servicios públicos o en sectores considerados estratégicos.

En cada uno de dichos sectores habrá que distinguir (1) de qué tipo de propiedad se trata; (2) qué tipo de administración pública es la más adecuada y (3) qué tipo de institución sería la más adecuada. En la Figura 1 se resumen las relaciones entre dichas variables.

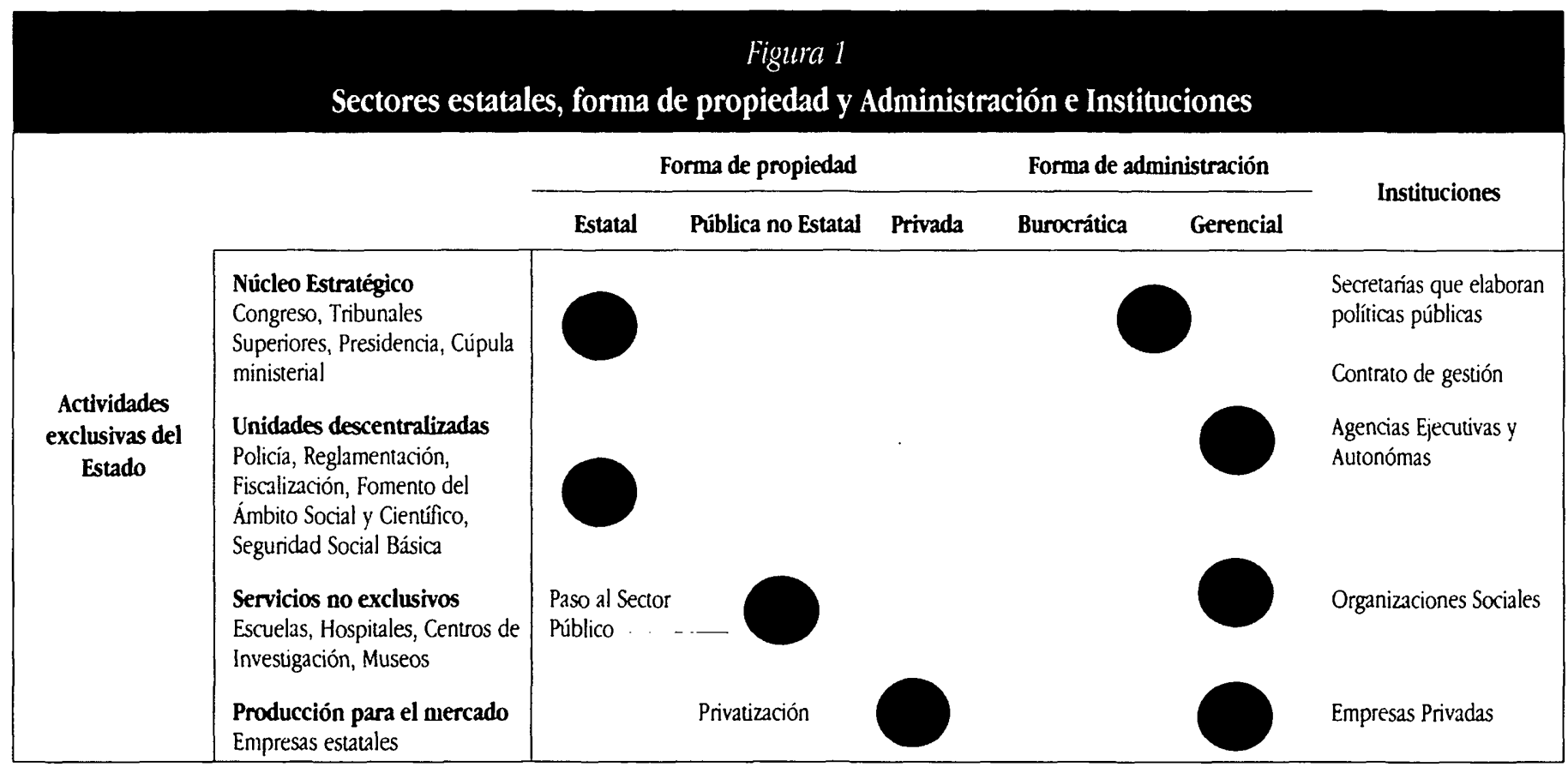

Fuente: Ministerio de la Administración Federal y de la Reforma del Estado (1995). Plan de Dirección para la Reforma del Estado.

En el núcleo estratégico y en las actividades exclusivas del Estado la propiedad deberá ser estatal por definición. Aparte de las herramientas tradicionales —aprobación de leyes (Congreso), elaboración de políticas públicas (presidencia y cúpulas ministeriales) y emisión de sentencias y acuerdos (poder judicial)— el nú- cleo estratégico hará uso de una nueva herramienta que la administración pública lleva poco tiempo utilizando: el contrato de gestión. Mediante el contrato de gestión, el núcleo estratégico va a definir los objetivos de las entidades ejecutoras del Estado y los respectivos indicadores de desempeño, además de 
garantizar a dichas entidades los medios humanos, materiales y financieros para poder alcanzarlos.

Esta reforma es más institucional que organizativa y de gestión. No se limita a proponer una restructuración que conlleve la introducción de modernas técnicas de gestión. Las nuevas instituciones son fundamentales para la reforma del Estado. Las instituciones descentralizadas serán respectivamente las agencias ejecutivas, en el sector de las actividades exclusivas del Estado, y las corganizaciones sociales* en las actividades sociales y científicas, que pertenecen al grupo de las no exclusivas del Estado.

En principio, las actividades exclusivas del Estado deberán organizarse a través del sistema de agencias ejecutivas", que podríamos llamar también agencias autónomas. ${ }^{21}$. Una agencia ejecutiva deberá tener un dirigente nombrado por el ministro correspondiente, con el que se negociará el contrato de gestión. Una vez se hayan establecido los objetivos y los indicadores de desempeño no sólo cualitativos sino también cuantitativos, el dirigente tendrá amplia libertad para gestionar el presupuesto global recibido; podrá gestionar a sus funcionarios con autonomía en lo que se refiere a admisión, exoneración y pago, y podrá realizar compras respetando los principios generales de licitación.

En el otro extremo, en el sector de bienes y servicios para el mercado, la producción deberá correr, en principio, a cargo del sector privado. Ése es el origen del programa de privatización en curso. Se presupone que las empresas serán más eficientes si son controladas por el mercado y administradas de forma privada. De aquí surge el principio de subsidiariedad: sólo debe ser estatal la actividad que el mercado no pueda controlar. Además, debido a la crisis fiscal del Estado, éste perdió la capacidad de realizar ahorros forzados y de invertir en las empresas estatales, por lo que se vuelve aconsejable privatizarlas. Esta política está de acuerdo con la concepción de que el Estado moderno, que se continuará en el siglo XXI, no será ni el Estado liberal que está más cerca, como poco, del siglo XIX, ni el Estado ejecutor del siglo $\mathrm{XX}$. Tendrá que ser un Estado regulador y transferidor de recursos, que garantice la financiación a fondo perdido de las actividades que el mercado no tiene posibilidades de llevar a cabo.

\section{Propiedad pública no estatal}

Para finalizar, debemos analizar el caso de las actividades estatales no exclusivas realizadas en los sectores social y científico. Lo que nosotros proponemos es que la forma de propiedad dominante debe ser la pública no estatal.

En el capitalismo contemporáneo no son únicamente dos las formas de propiedad relevantes, como generalmente se piensa, y como sugiere la división clásica del Derecho en Derecho Público y Derecho Privado - la propiedad privada y la pública-, sino tres: (1) la propiedad privada, encaminada a obtener lucro (empresas) o al consumo privado (familias); (2) la propiedad pública estatal: y (3) la propiedad pública no estatal, que también se puede llamar no gubernamental, sin ánimo de lucro, o propiedad del tercer sector. La confusión deriva de la división tripartita del Derecho. Los tipos de propiedad y sus respectivas organizaciones se definen generalmente de acuerdo con la ley que los regula (Derecho Público o Privado), y no por sus objetivos. Según cuáles sean sus objetivos, una organización será privada cuando esté encaminada a la consecución de beneficios y pública cuando su finalidad sea servir al interés público. En términos legales, una organización es privada cuando es propiedad privada de individuos, como es el caso de las empresas e incluso de las cooperativas, y pública cuando pertenece a la comunidad, a la población ${ }^{22}$.

Al decir esto, estoy afirmando que lo público no se confunde con lo estatal. El espacio público es más amplio que el estatal, ya que puede ser estatal o no estatal. En un plano ideal, lo estatal es siempre público, cosa que en la práctica no es así: el Estado precapitalista era, en última instancia, privado, ya que el sentido de su existencia era atender las necesidades del príncipe. En el mundo contemporáneo lo público se ha separado conceptualmente de lo privado, aunque todos los días seamos testigos de los intentos de apropiación privada del Estado.

Es pública la propiedad que es de todos y para todos. Es estatal la institución que detenta el poder de legislar y fijar impuestos. Es estatal la propiedad que forma parte integrante del aparato del Estado, y que se rige por el Derecho Administrativo ${ }^{23}$. Es privada la propiedad cuya finalidad es la consecución de lucro o el consumo por parte de individuos o grupos. De acuerdo con esta concepción, una fundación "de Derecho Privado", aunque se rija por el Derecho Civil, como son, por ejemplo, las universidades norteamericanas, es una institución pública, en la medida en que su fin último es el interés general ${ }^{24}$. En principio, todas las organizaciones sin ánimo de lucro son o deben ser organizaciones públicas no estatales ${ }^{25}$. Podríamos afirmar sin duda que al final seguimos teniendo solamente dos clases de propiedad: la pública y la privada, aunque con dos importantes salvedades: en primer lugar, la propiedad pública se subdivide en estatal y no estatal, en lugar de confundirse con la estatal; y segundo punto, las instituciones de Derecho Privado centradas en el interés público y no en el consumo privado no son privadas sino públicas no estatales. El reconocimiento de la existencia de un espacio público no estatal cobró especial importancia en un momento en que la crisis del Estado agravó la dicotomía Estado-sector privado, lo que condujo a muchos a pensar que la única altemativa a la propiedad estatal era la privada. La privatización es una alternativa adecuada cuando la institución puede 
obtener la totalidad de sus ingresos de la venta de sus productos y servicios, y el mercado está preparado para asumir la coordinación de sus actividades. Cuando éste no es el caso, lo público no estatal puede hacer su entrada. Por otro lado, en los momentos en que la crisis del Estado hace necesario que se examinen de nuevo las relaciones Estado-sociedad, el espacio público no estatal puede cumplir una función de ‘paso intermedio. o facilitar la aparición de formas de control social directo y de cooperación, que abren nuevas perspectivas para la democracia. Según señala CuNIL GRAU (1995: 31-32):

"La introducción de "lo público" como una tercera dimensión que va más allá de la visión dicotómica que enfrenta de forma absoluta lo "estatal" y lo "privado" está indudablemente vinculada a la necesidad de redefinir las relaciones entre el Estado y la sociedad ... Lo público, "en el Estado" no es un dato definitivo, sino un proceso de consirucción que a su vez supone que la esfera pública social tome parte activa en la tarea que le corresponde de influir en las decisiones estatales."

En el sector de los servicios estatales no exclusivos, la propiedad deberá ser, en principio, pública no estatal. No debe ser estatal porque no implica el uso del poder del Estado. Y no debe ser privada porque presupone transferencias del Estado. Debe ser pública para justificar las subvenciones recibidas del Estado. El hecho de ser pública no estatal implicará a su vez, por imperativos de la actividad, el ser controlada de forma conjunta por el mercado, por el Estado y principalmente por la sociedad. Mientras que el control ejercido por el Estado vendrá necesariamente precedido por el control social directo, derivado del poder de los consejos de administración formados por la sociedad. Y el control del mercado se materializará en el cobro de los servicios. De esta forma, la sociedad estará permanentemente confirmando la validez de los servicios prestados, a la vez que se establecerá un sistema de cooperación o de cogestión entre el Estado y la sociedad civil.

Dentro de la Unión, los servicios no exclusivos del Estado, más relevantes son las universidades, las escuelas técnicas, los centros de investigación, los hospitales y los museos. La reforma que se ha propuesto es transformarlos en un tipo especial de entidad no estatal, las organizaciones sociales. La idea es transformarlos voluntariamente en "organizaciones sociales", o sea, en entidades que firmen un contrato de gestión con el poder ejecutivo y que cuenten con la autorización del Parlamento para tener participación en el presupuesto público. La organización social no es en realidad un tipo de entidad pública no estatal, sino una propiedad de dichas entidades, declarada por el Estado.

La ampliación de la esfera pública no estatal que aquí proponemos no significa en absoluto la privatización de actividades del Estado. Al contrario, se trata de ampliar el carácter democrático y participativo de la esfera pública, subordinándola a un Derecho Público renovado y ampliado. Según señala TarSO GENRO (1996):

- La reacción social causada por la exclusión, la fragmentación, junto al surgimiento de nuevos modos de vida en común (que buscan al influir en el Estado rescatar la ciudadania y la dignidad social del grupo) contribuyen a la aparición de una nueva esfera pública no estatal ... Surge entonces un nuevo Derecho Público como respuesta a la impotencia del Estado y de sus mecanismos de representación politica. Un Derecho Público cuyas reglas son formalizadas a veces $y$ otras veces, no, pero que constituyen un ensayo de un proceso de gestión conjunta, que combina democracia directa - de participación voluntaria- con una representación política prevista en las normas escritas procedentes de la voluntad estatal.

La transformación de los servicios estatales no exclusivos en propiedad pública no estatal y su declaración en organización social se hará a través de un oprograma destinado a la devolución al sector público", que no debe confundirse con el programa de privatización, en la medida en que las nuevas entidades conservarán su carácter público y el Estado se seguirá haciendo cargo de su financiación. Dicho proceso deberá asegurar el carácter público aunque de Derecho privado de la nueva entidad, asegurándole así una mayor autonomía administrativa y financiera. Para esto se tendrá que hacer desaparecer las entidades existentes actualmente y sustituirlas por fundaciones públicas de Derecho privado instituidas por el Estado y, por lo tanto, sometidas a todas las restricciones impuestas por la administración estatal ${ }^{26}$. Las nuevas entidades recibirán por cesión precaria los bienes de la entidad extinta. Los actuales funcionarios de la entidad pasarán a ser una categoría en extinción y pasarán a disposición de la nueva entidad. El presupuesto de la organización social será global. La contratación de nuevos empleados se llevará a cabo de acuerdo con el régimen de Consolidación de las Leyes del Trabajo (CLT). Las compras se subordinarán a los principios de la licitación pública, aunque podrán contar con un régimen propio. El control de los recursos estatales puestos a disposición de la organización social se hará a través de contrato de gestión, además de estar supervisado por el órgano de control interno y por el Tribunal de Cuentas.

Las organizaciones sociales serán organizaciones públicas no estatales, más concretamente fundaciones de Derecho privado que firman un contrato de gestión con el poder ejecutivo, con la aprobación del poder legislativo ganándose así el derecho de participar del presupuesto público federal, de los estados o municipal. La autonomía de la organización social conllevará una mayor responsabilidad por parte de sus gestores. Por otro lado, la idea implica un mayor control social y una mayor cooperación con la sociedad, ya que el Estado deja de dirigir directamente la institución. 
En el proceso de edevolución al sector público -transformación de entidades estatales de servicio en entidades públicas no estatales- lo importante es evitar la privatización y la feudalización de las organizaciones sociales, o sea, la apropiación de éstas por grupos de individuos que las utilizan como si fuesen privadas. La feudalización se da cuando ese grupo, aunque su actuación se mueve en interés público, se perpetúa al mando de la organización, independientemente de su capacidad de gestión.

\section{La reformid constitucional}

La reforma más importante, porque de ella depende la mayor parte de las otras, es, claro está, la constitucional. Aparte de su significado administrativo, su contenido político es evidente. En la medida en que se aprueben sus principales propuestas - la flexibilización de la estabilidad, el fin del régimen jurídico único, el fin de la isonomía como precepto constitucional, el refuerzo de los techos salariales, la elaboración de un sistema de remuneración más claro, la necesidad de aprobar un proyecto de ley para aumentar las remuneraciones en los tres poderesno sólo se abrirán las puertas a la administración pública basada en la gestión, sino que además la sociedad y sus representantes políticos señalarán así su compromiso con una administración pública renovada, con un nuevo Estado moderno y eficiente.

El sistema actual es rígido: todos los funcionarios son fijos, lo que sólo puede cambiar en el caso de que se pruebe, en proceso administrativo, que han cometido una falta grave. La lista de faltas en las que se puede incurrir es extensa y en ella aparece, por ejemplo, la desidia. La realidad es, sin embargo, que sólo se despide a quien haya robado, ofendido a otro grave y públicamente, o abandonado sin razón el puesto de trabajo. Si el funcionario ha cometido alguna de estas cosas, se le podrá despedir sin ningún derecho. En los demás casos, ya sea porque resulta difícil de probar, o porque existe una complicidad generalizada que hace inviable el despido, no se despide a nadie. En la propuesta de reforma el gobiemo ha abandonado ese todo o nada, por el cual el funcionario conserva su empleo o pierde todos sus derechos, para pasar a un sistema gradualista, semejante al que ya ha adoptado el sector privado. Se crean dos nuevas razones de despido, además de la falta grave: el despido por rendimiento insuficiente y la baja debida al excesivo número de mandos. Para dejar bien claro que el despido por rendimiento insuficiente no es lo mismo que la falta grave, el funcionario tendrá derecho, en el primer caso, a una pequeña indemnización. Esta indemnización será de menor cuantía si la causa de la partida es el número excesivo de mandos, ya que en este caso el funcionario no es personalmente responsable de su baja.

El despido por rendimiento insuficiente se examinará caso por caso. El objetivo de esta medida será permitir que el administrador público pueda exigir trabajo al funcionario para rentabilizar la administración pública basada en la gestión. Por su lado, la baja por exceso de mandos no se tratará de forma personal, destinándose más bien a grupos de funcionarios. El objetivo es reducir costes, garantizar que los contribuyentes no se vean obligados a pagar por funcionarios que el Estado no necesite. En el segundo caso, la indemnización equivaldrá, en principio, a un salario por año trabajado y, en el primer caso, a la mitad de dicha cantidad.

Sólo se podrá despedir al funcionario por rendimiento insuficiente si se le somete a un proceso de evaluación formal, teniendo siempre derecho a un proceso administrativo con una amplia defensa. La finalidad de este dispositivo es que los administradores públicos reciban los frutos del trabajo de los funcionarios. La motivación de los funcionarios debe ser sobre todo positiva - basada en que su trabajo tiene un sentido, en las oportunidades de ascenso y en el reconocimiento salarial一, pero es esencial que también exista la posibilidad de penalización. Mediante la destitución debida al excesivo número de mandos ya se va a conseguir reducir el déficit público, adecuando el número de funcionarios a las necesidades reales de la administración. La decisión debe tomarse de forma totalmente fría basándonos en criterios generales (p.ej.: los más jóvenes, o los últimos que hayan entrado a trabajar y que no tengan personas a su cargo), con el fin de evitar la persecución política. Los criterios impersonales evitarán las largas quejas ante la Justicia, pues harán imposible que se despidan fúncionarios escogidos por los jefes de acuerdo con sus criterios que siempre serían en mayor o menor medida subjetivos.

Una alternativa sería combinar los criterios impersonales con una evaluación del rendimiento. Aunque esta alternativa presente ciertos atractivos, la realidad es que resulta incompatible con la baja debida al excesivo número de mandos, que acabaría quedándose en despido por rendimiento insuficiente. Todos los funcionarios afectados alegarían inmediatamente que eran víctimas de persecución por causa de sus ideas políticas, a lo que seguirían largas acciones judiciales, que frustraría el objetivo de la baja, es decir, reducir mandos y gastos. Según se describe en la propuesta del gobierno, una vez se haya decidjdo dar de baja a un determinado número de funcionarios, sus respectivos cargos desaparecerán, y no podrán crearse nuevamente durante un período de cuatro años. De esta forma se evita el despido por motivos políticos.

Estos cambios no se introducen sólo en beneficio del interés público y de los ciudadanos, sino también en beneficio del funcionario. Todos los funcionarios competentes y trabajadores, 
que valoran su propio trabajo, saldrán beneficiados. Sabrán que están llevando a cabo una labor necesaria, al tiempo que recuperan el respeto de la sociedad - un respeto que se perdió cuando una minoría de funcionarios sin interés, cuyo trabajo no contribuyó en nada a la mejora de las cosas, estableció patrones de ineficacia y de atención inadecuada que dio una imagen errónea del conjunto de los funcionarios.

Resulta importante señalar, de todas formas, que a pesar de que se haya flexibilizado la situación, los funcionarios siguen manteniendo sus plazas fijas, en la medida en que sólo se les puede despedir en los términos expresados por la ley. En el caso de que se produzca algún abuso contra sus derechos, la justicia siempre podrá devolverle a su puesto, al contrario de lo que ocurre en el sector privado donde no hay puestos fijos y el trabajador despedido casi no tiene derecho a indemnización. El mantenimiento de los puestos fijos no sólo responde a una voluntad de diferenciar a la administración pública de la privada, sino también a la mayor necesidad de seguridad que caracteriza en todo el mundo al trabajo de los funcionarios del Estado. Éstos muestran una tendencia hacia el servicio público: están dispuestos a tener una vida modesta, pero en compensación esperan más seguridad. Más seguridad, por ejemplo, que la que tienen los políticos o los empresarios. Sin embargo, esta seguridad no puede ser absoluta. El Estado garantiza un puesto fijo a sus funcionarios porque de esa manera asegura más independencia o autonomía a su actividad pública, al ejercicio del poder del Estado del que se les inviste, pero no la garantiza en aras de una necesidad exagerada de seguridad personal y mucho menos para imposibilitar la retribución en trabajo por parte del funcionario, ni para justificar la perpetuación del número excesivo de mandos.

\section{Cobertura pública}

La reforma del sistema de cobertura social de los funcionarios resulta fundamental, en la medida en que constituye un paso indispensable en la superación de la crisis fiscal del Estado. En un último análisis la crisis del sistema de cobertura tiene su origen en una concepción errónea de lo que significa jubilación. Un sistema de pensiones existe para garantizar una jubilación digna a personas que han llegado a la vejez y ya no pueden trabajar, no para garantizar un sobresueldo a personas que aún podrían trabajar largo tiempo: su finalidad no es jubilar personas, en concreto, funcionarios del Estado, a los 50 años de edad.

Los sistemas de jubilación garantizados por el Estado en todo el mundo no son sistemas de capitalización sino, en principio, sistemas de repartición en los que los funcionarios activos pagan la jubilación de los inactivos. Se prefiere el sistema de repartición porque el Estado, que generalmente está en condiciones de garantizar la marcha del sistema, es un mal gestor de los fondos de capitalización. Por otro lado, un sistema de capitalización sólo es legítimo cuando los que participan del fondo dependen realmente de la rentabilidad del mismo. La cuestión es que resulta difícil, por no decir imposible, decir a los funcionarios que su jubilación dependerá de la destreza que muestre el Estado para administrar el posible fondo de capitalización. De acuerdo con el sistema de repartición, sin embargo, es necesario que exista un equilibrio entre el número de jóvenes, que pagan el sistema en términos de funcionamiento y el número de viejos que se benefician de la jubilación.

En Brasil se estableció un sistema de privilegios dependiente del sistema de jubilación de los funcionarios públicos, que se tradujo en la existencia de jubilación con sueldo íntegro independientemente de la contribución, y en la posibilidad de jubilarse muy pronto. Mientras que los trabajadores más pobres del sector privado rural se jubilan a los 62 años por término medio, los funcionarios públicos pueden jubilarse con el sueldo completo a una edad de poco más de 50 años, jlos altos funcionarios antes de los 50 años! Por otro lado, el beneficio medio del jubilado de la Unión, o federal, es 8,1 veces mayor que el beneficio del jubilado del INSS, mientras que la contribución media del funcionario federal es 3,4 veces mayor que la de los asegurados por el INSS.

El sistema de cobertura privado ha conseguido mantener a lo largo de los años un relativo equilibrio financiero debido a la pirámide de edad achatada que prevalece aún en el país. Sin embargo, con la reducción de la tasa de la natalidad, dicha estructura está variando muy rápidamente. Por eso la cobertura muestra ya signos de crisis. Una crisis que tenderá a agravarse a medida que la relación existente entre el número de jóvenes, que son los que tienen que pagar por la cobertura, y el número de jubilados vaya acercándose más. En los años 50 la relación era de 8 a 1, en la actualidad es de 2 a 1 ; pronto será de 1 a 1 , y el sistema será inviable.

En el caso de la cobertura pública el desequilibrio es ya total: las contribuciones de los funcionarios sumadas a una contribución virtual del Estado, que supone el doble de la primera financian casi una quinta parte del coste anual de la nómina de inactivos y pensionistas. No obstante, el sistema sobrevive porque el Tesoro paga la diferencia. Ésta es realmente una situación inicua -al final los contribuyentes están pagando para que los funcionarios se jubilen con privilegios- que ya se ha vuelto insostenible desde el punto de vista fiscal: el sistema de jubilaciones del funcionariado público produce un agujero anual en la hacienda pública correspondiente a casi un $2 \%$ del PIB. 
Para hacer desaparecer, a medio plazo (a conto es imposible) ese desequilibrio surgido de un sistema de privilegios, deberán aplicarse a la cobertura pública con rigurosidad las dos reglas que se prevé aplicar a la cobertura privada: (1) la jubilación debe ser por edad, de forma que los funcionarios se jubilen en torno a los 60 años, diez años más tarde que lo que ocurre hoy; y (2) el importe de la jubilación, basado en los últimos sueldos, deberá ser proporcional a lo que haya contribuido y no íntegro, como prevé la Constitución de 1988.

Sólo así se podrá garantizar un coste razonable para el sistema de cobertura pública. Mientras tanto, el Estado deberá seguir garantizando el sistema. No tiene sentido exigir de los funcionarios del Escado - una institución que, al contrario que la empresa privada, puede garantizar un sistema de coberturaque recurra obligatoriamente a los fondos complementarios de cobertura. El Estado garantizará la jubilación de sus funcionarios, independientemente del régimen jurídico al que se acojan. Para calcular cuánto tendrá que recibir un funcionario al jubilarse, será necesario hacer un cálculo actuarial. Si se toma en consideración la contribución de los funcionarios a su jubilación (en torno al 11\% de los sueldos) y del Estado y la edad media en que el funcionario empieza a contribuir, se jubila y fallece, y considerando una aportación razonable del fondo virtual (ya que el sistema debe ser de repartición), se podrá calcular y establecer por ley la proporción de la media de los últimos sueldos, que va a constituir su jubilación. Cálculos iniciales realizados indican que dicho porcentaje deberá girar en torno al $80 \%$.

Los derechos adquiridos y las expectativas de derechos se respetarán totalmente. Los funcionarios que ya tengan derecho a jubilarse, antes de la Constitución, se jubilarán de acuerdo con las normas actuales, incluso aunque decidan hacerlo dentro de muchos años, cuando alcancen la edad establecida para ello. Éste es un derecho adquirido. Por otro lado, las expectativas de derecho se garantizarán de forma proporcional. Un funcionario, por ejemplo, que empezó a trabajar a los 17 años, tiene hoy derecho a jubilarse, según el sistema actual, a los 52 años. Según el nuevo sistema, tendrá derecho a jubilarse, alrededor de los 58 años (60 años, menos una reducción por el tiempo trabajado,que fue largo). ¿Con qué sueldo se jubilaría un funcionario que haya entrado a los 17 años, que en el momento de la enmienda constitucional hubiera cumplido 17 años y medio de servicio público?' Dado qué se garantizarán las expectativas de derecho, su jubilación, calculada mediante una simple regla de tres, tendrá lugar en torno a los 55 años. Para determinar la cuantía de la jubilación habrá que realizar el mismo tipo de cálculo: tendrá que ser úna cantidad intermedia entre la jubilación íntegra más el 20\% que existe hoy y la jubilación en torno al $80 \%$ que va a caracterizar al nuevo sistema.

\section{Tres proyectos fundamentales}

Hay aún tres proyectos esenciales, aparte de la reforma constitucional que acabo de esbozar, para llevar a cabo la reforma del aparato estatal brasileño: la descentralización de los servicios sociales a través de las organizaciones sociales, la puesta en marcha de las actividades exclusivas del Estado a través de las agencias ejecutivas. y el fortalecimiento del núcleo estratégico del Estado mediante la contratación, la formación y una buena remuneración destinadas a profesionalizar cada vez más la figura del funcionario público.

El primer proyecto se centra en la descentralización de los servicios sociales del Estado, por un lado, respecto a los estados y municipios y, por otro, del Estado propiamente dicho, respecto al sector público no estatal. Esta última reforma se llevará a cabo mediante la concesión de un alto grado de autonomía financiera y administrativa a las entidades de servicio del Estado, en especial, de servicio social, como las universidades, las escuelas técnicas, los hospitales, los museos, los centros de investigación y el mismo sistema de cobertura social. Con este objetivo, la idea es crear la posibilidad de que dichas entidades se transformen en "organizaciones sociales".

El segundo proyecto trata de las agencias ejecutivas. La necesidad de aumentar el grado de autonomía y la consiguiente responsabilización por resultados han llevado a la elaboración de este proyecto, cuyo objetivo es transformar los ayuntamientos y fundaciones que ejerzan actividades exclusivas del Estado en agencias con amplia libertad para gestionar sus propios recursos humanos y financieros, partiendo de un presupuesto global. Dentro del proyecto de las agencias ejecutivas se está trabajando en dos planos diferentes. En primer lugar, se están elaborando los instrumentos legales necesarios para que las transformaciones que se buscan sean viables, además de un estudio de la legislación, normas y reglamentos existentes, cuya finalidad es poder superar los obstáculos que pudieran encontrarse en ellos, para irles concediendo gradualmente dispensas de controles burocráticos y asegurarles autonomía administrativa y responsabilidad. Simultáneamente se han comenzado a aplicar los nuevos enfoques en algunos ayuntamientos escogidos, que se convertirán en laboratorios de pruebas.

Por último, el tercer proyecto prioritario es el fortalecimiento del núcleo estratégico del Estado, destinado a completar el proceso de profesionalización del administrador público. Ya existen profesiones relativamente bien estructuradas como puede ser la militar, la policía, los jueces, promotores, procuradores, fiscales y diplomáticos. No está clara la profesión de administrador público de alto nivel. La idea es desarrollar dicha profesión a partir de las profesiones que ya existen, y que fueron creadas a finales de los 80 , como los gestores gubernamentales, los ana- 
listas de control y finanzas y los analistas de presupuesto. Ya se han dado los primeros pasos en esa dirección con el plan de convocatorias de oposiciones anuales para estos puestos, para los que ya se han fijado plazos de inscripción y la cantidad de plazas que se van a abrir hasta 1999. Se exigirá un nivel de estudios de posgraduado en administración pública o en economía para presentarse a la oposición. Los altos administradores ocuparán los cargos más altos en todos los sectores de la administración pública, donde se necesitan administradores generalistas, administradores financieros y de control, y administradores de presupuesto y programación económica. Saldrán principalmente de los alumnos de maestría profesional en administración pública, economía y ciencias políticas.

\section{Conclusión: perspectivas ofrecidas por la reforma}

Esta propuesta de reforma del aparato estatal se materializó en el Plan de Dirección para la Reforma del Estado, elaborado por el Ministerio de la Administración Federal y Reforma del Estado, aprobado en septiembre de 1995 por la Cámara de Reforma del Estado ${ }^{27}$ (Ministerio de la Administración Federal y Reforma del Estado, 1995). En este sentido, en junio de 1995 el gobierno envió su propuesta de reforma constitucional, que fue aprobada en octubre de ese mismo año en la Comisión de Justicia después de haber sufrido ligeras modificaciones. A finales de año se nombró al encargado de realizar el informe relativo a la reforma, que lo terminó tres meses después. En el informe se mantenian la mayor parte de las propuestas del gobiemo, se perfeccionaban algunos aspectos y se dejaba en el aire el tema más espinoso: la modificación del estatuto vitalicio de los funcionarios. Por otro lado, no será posible votar la reforma administrativa hasta abril de 1997 por las dificultades con las que tuvo que enfrentarse el gobierno debido a la reforma de la cobertura social y la imposibilidad en la práctica de votar dos reformas de tal envergadura al mismo tiempo. Los reveses que el gobierno sufrió durante la reforma de sistema de cobertura lo debilitaron políticamente, y dejaban entrever grandes dificultades en lo que se refiere a la votación de la reforma administrativa, a pesar del fuerte apoyo que dicha reforma estaba recibiendo por parte de la opinión pública y de los gobernadores de los estados.

Por otro lado, alli donde se chocaba directamente con la Constitución, en las ideas relativas a la reducción de costes de la administración federal, al fortalecimiento del núcleo estratégico, a la implantación de agencias ejecutivas y organizaciones sociales era donde, tanto a nivel federal como a nivel de estados y munici- pios, el desbordamiento de los costes de personal indicaba que la necesidad de una reforma era acuciante. Los estados en especial comenzaron a tomar diversas medidas para provocar la desaparición de marajás, sobre todo entre los jubilados pertenecientes a la Polícia Militar y al Poder Judicial. Pusieron en marcha, asimismo, programas de despido voluntario, mientras esperaban la llegada de la reforma constitucional.

A nivel federal y en lo relativo a las organizaciones sociales, fue evidente desde mediados de 1995 que no sería posible implantarlas en las universidades federales, dada la resistencia de profesores y funcionarios, que identificaron el proceso de adevolución al sector público, propuesto, con un proceso de privatización. En realidad, la resistencia al cambio en ese ámbito tiene que ver con la concepción burocrática del Estado brasileño que aún subsiste en nuestras élites, según la cual ciertas instituciones que prestan servicios fundamentales al Estado, siendo pagadas por ello, como es el caso de las universidades federales, deben tener el monopolio del dinero que el Estado destina a dicho sector en este caso, el monopolio de los recursos dedicados a la enseñanza y a la investigación. Mientras no se modifique ese tipo de cultura burocrática, y mientras la amplia mayoría no entienda que quien presta un servicio al Estado debe hacerlo de forma eficiente y competitiva, será difícil convertir al Estado brasileño en una institución realmente democrática, al servicio de los ciudadanos, y no en una organización al servicio de los funcionarios y capitalistas que tienen suficiente poder para privatizarlo.

Casi dos años años después de su puesta en marcha, hoy puedo afirmar que las perspectivas relativas a la reforma de la administración pública son muy favorables. Cuando el nuevo gobierno planteó el problema, a principios de 1995, la reacción inicial de la sociedad fue de recelo, si no de irritación. La verdad es que sobre mí cayeron rayos y truenos. La prensa adoptó una actitud escéptica, por no decir que abiertamente agresiva. Varias personas me sugirieron que debía hablar menos y hacer más, como si fuese posible cambiar la Constitución sin provocar antes un gran debate público. Achaqué esta reacción natural a la resistencia al cambio. Estaba proponiendo un tema nuevo para el país. Un tema que nunca se había discutido en profundidad, que no fue objeto de discusión pública en la Constituyente; que no se trató como problema nacional en la campaña presidencial de 1994; que aparecía sólo de forma marginal en los programas de gobierno; en resumen, que no estaba entre los puntos que el país había calificado como prioritarios ${ }^{28}$.

A la resistencia al cambio se debe haber sumado un segundo factor. Según PrzFworsk (1995), el éxito de la reforma del Estado depende de la capacidad de respuesta de los ciudadanos. La cuestión es que la cultura política de Brasil siempre fue más autoritaria que democrática. Históricamente el Estado no se veía como un órgano unido a la sociedad, nacido de un contrato social, sino como una entidad situada por encima de la so- 
ciedad. Así, tal como señala Luciano MarTass (1995a: 35): •muy rara vez se exigió la responsabilidad política generada por la administración de los recursos públicos como un derecho inherente al ciudadano. La realidad es que el principio de que no bay tributación sin representación es completamente ajeno a la cultura política brasileña. No nos sorprende, por tanto, que la reacción inicial a las propuestas, cuando aún se estaban elaborando, fuese tan negativa.

Mientras tanto y después de que el gobiemo insistiera durante varios meses, empezó a surgir el apoyo: de los gobernadores, de los prefectos, de la prensa, de la opinión pública, y de las altas esferas de la administración pública. A finales de 1996 existía el convencimiento no sólo de que la reforma constitucional cumplía muchos requisitos para ser aprobada en el Congreso, sino también que era fundamental para el ajuste fiscal de los estados y municipios, además de ser esencial para impulsar la transición de una administración pública burocrática, lenta y poco eficiente, hacia una administración pública basada en la gestión, descentralizada, eficiente, y centrada en la atención al ciudadano. La resistencia a la reforma se concentraba ahora sólo en dos frentes: por un lado, en los sectores medios y bajos de los funcionarios, en la persona de sus representantes corporativos, sindicales y partidistas, que se llaman a sí mismos de izquierda; y por otro lado, en el clientelismo patrimonialista aún vivo, que temía por la suerte de sus beneficiarios, muchos de los cuales son cabezas electorales o familiares de políticos de la derecha.

En el proceso de reforma es fundamental contar con el apoyo de la alta burocracia -un apoyo que se está consiguiendo-. En Inglaterra, por ejemplo, no fue posible la reforma hasta que la alta administración pública británica decidió que había llegado el mo- mento de introducir reformas, y que para ello era conveniente una alianza con el Partido Conservador, que llegó al gobiemo en 1979. En un sentido más amplio, resulta fundamental el apoyo de las élites modemizadoras del país, en las que se incluye la alta administración pública. De acuerdo con lo que señala $\mathrm{P}$ QUET CaRNEIRo (1993: 150) en las dos reformas administrativas federales (1936 y 1967): estuvo presente la acción decisiva de una élite de administradores, economistas y políicos - autoritarios o nofavorables a la cuestión de la organización del Estado, y entre ellos prevaleció el diagnóstico común de que las estructuras existentes eran insuficientes para institucionalizar el proceso de reforma.

Después de un período natural de desconfianza hacia una nueva idea, el apoyo se ha manifestado de las formas más diversas. Ese apoyo parte de la convicción de que el modelo implantado en 1988 no fue realista, y que agravó el problema, en lugar de resolverlo. El gran enemigo no es solamente el patrimonialismo, sino también el burocratismo. El objetivo de instalar una administración burocrática en el país sigue vivo, pues nunca se logró terminar esa tarea, aunque en 1995 se hizo evidente que para conseguirlo es necesario dar un paso más allá y caminar hacia la administración pública basada en la gestión, que engloba y flexibiliza los principios burocráticos clásicos. Una encuesta realizada hace poco entre las élites brasileñas ha indicado que existe un gran apoyo a la reforma, en especial entre los empresarios y los altos administradores públicos (IBEP, 1997). Por todo ello y, a pesar de las dificultades con las que se ha tenido que enfrentar la reforma, ya haya sido en el Congreso o en su aplicación práctica en la administración, existen razones para mirar al futuro con optimismo. La realidad es que hoy en día en Brasil hay un proceso de reforma basada en la gestión en marcha.
- Este trabajo fue presentado como Comunicación en el Congreso de la Asociación Intemacional de Ciencias Políticas. IPSA, Seul, agosto 1997.

* Ministro de la Administración Federal y de la Reforma del Estado. Profesor de la Fundación Getúlio Vargas, Sào Paulo.

1 Como señaló Femando Henrique Cardoso (1996: A10): va globalización ha cambiado la función del Estado ... el énfasis de la intervención gubemamental está ahora puesto casi exclusivamente en cómo hacer posible que las economias nacionales desarrollen y mantengan caracteristicas estructurales que favorezcan la competitividad a escala global.

- Para una cŕ́tica del concepto de gobemabilidad relacionado con el equilibrio entre lo que se exige del gobiemo y su capacidad de atender dichas demandas, que viene de HUNTINGTON (1968), ver DINIZ (1995).

"En nuestra opinión, está claro que, como señala Frischtack (1994: 163), ‘el desafio crucial reside en obtener esa forma específica de ariculación entre la maquinaria estatal y la sociedad en la que se admita que el problema que plantea una organización eficiente no se puede disociar del problema político. Sin embargo, no vamos a centramos en esa ariculación.
4 La expresión organización no gubernamental (ONG) podrá considerarse sinónimo de organización pública no estatal (OPNE). OPNE sería simplemente una forma más precisa de referirse a las entidades del sector terciario sin fines lucrativos, en las que (1) no se confunde Estado con gobiemo, y (2) aparece resaltado el carácter público, en interés de todos, de este tipo de organización voluntaria. En la práctica, las ONGs pretenden ser y son una forma •más modema. de actuación, en especial en los ámbitos de la educación, la salud, el medio ambiente y la asistencia social. El término no abarca a pequeñas instituciones asistenciales ni a grandes fundaciones, aunque éstas también son OPNEs.

"Ésta fue una forma equivocada de entender lo que es la administración pública basada en la gestión. Como la contratación de los burócratas se realizó a través de las empresas estatales, se impidió la creación de cuerpos burocráticos estables dotados de profesiones flexibles con posibilidades de acceso más rápidas que las profesiones tradicionales, pero profesionales, al fin y al cabo. Según señala SavTos (1995): .la función de agentes de la burocracia estatal pasó a manos de un grupo de técnicos, de origen y formaciones heterogéneos, pero a quienes se identificó de forma global con la llamada tecnocracia, que floreció especialmente en la década de los 70 . Esta tecnocracia, procedente de los medios académicos, del sector privado, de las (mismas) empresas estatales y de los órganọs del gobierno, proporcionó a la administración fe- 
deral los mandos que iban a ocupar los altos cargos de la administración. Acerca de esta tecnoctacia estatal ver los trabajos clásicos de MARTINS (1973: 1985) y NuNES (1984).

${ }^{6}$ En palabras de Nilson Holavda (1993: 165): :La capacidad de gestión del Estado brasileño nunca se vio tan debilitada. La evolución que ha tenido lugar en los últimos años, y especialmente a partir de la llamada Nueva República, ha traido consigo un empeoramiento progresivo de la situación, y no existe, ni dentro ni fuera del gobierno, ninguna propuesta que sea capaz de invertir, a conto o medio plazo, dicha tendencia involucionista.

' Una excepción a esta generalización la constituye la reforma del sistema financiero nacional realizada entre 1983 y 1988 , que tenía como objetivo la creación de la cuenta movimiento del Banco de Brasil, de la Secretaria del Tesoro, la eliminación de presupuestos paralelos, en especial del apresupuesto monetario y la implantación de un excelente seguimiento y control informatizado del sistema de gastos: el SIAFI (Sistema Integrado de Administración Financiera). Estas reformas, llevadas a cabo por un destacado grupo de burócratas con Mailson da Nóbrega, Joào Batista Abreu, Andréa Calabi y Pedro Parente a la cabeza, se describen en GouvÊA (1994).

${ }^{8}$ Más concretamente, en 1936 se creó el Consejo Federal del Servicio Público Civil, que en 1938 fue reemplazado por el DASP. Los promotores de esta reforma fueron Mauricio Nabuco y Luiz Simòes Lopes, durante el primer gobiemo Vargas.

9 El DASP desapareció en 1986, dando paso a la SEDAP — Secretaría para la Administración Pública de la Presidencia de la República - que desaparece a su vez, en enero de 1989, pasando a formar parte de la Secretaria de Planificación de la Presidencia de la República. En marzo de 1990 se crea la SAF-Ministerio de Trabajo. En enero de 1995, con la entrada del gobierno de Femando Henrique Cardoso, la SAF se convierte en MARE -Ministerio de la Administración Federal y de la Reforma del Estado-

in Beltrào participó en la reforma administrativa de 1967 y después, con el cargo de Ministro de la Desburocratización, entre 1979 y 1983, se convirió en heraldo de las nuevas ideas. Definió su Programa Nacional de Desburocratización, puesto en marcha en 1979, como una propuesta política encaminada a utilizar la administración pública como medio para retirar al usuario del sistema democrático de su condición colonial de súbdito para investirlo ciudadano, destinatario de todas las actividades del Estado.

$"$ Según BeRTERo (1985: 117): edetrás de la decisión de diseminar la administración pública mediante la administración indirecta se encuentra el reconocimiento de que la administración directa no había sido capaz de responder con agilidad, flexibilidad, rapidez y creatividad a las demandas y presiones de un Estado que habia optado por apostar por el desarrollo.

1. En los años 70 se acuñaron varios denominaciones y conceptos para designar esta alianza: Fernando Henrique Cardoso se refirió a ella utilizando el concepto de anillos burocráticos. Guillermo O'Donnell la interpretó como un régimen burocrático autoritario. Yo siempre hablé de •modelo tecnoburocrático-capitalista. Peter Evans fijó el concepto de triple alianza.

${ }^{13}$ A pesar de que el Decreto-ley 200 hacia referencia a la formación de altos cargos administrativos (art. 94, V) y a la creación de un Centro de Perfeccionamiento del DASP (art. 121).

${ }^{14}$ El régimen militar siempre procuró evitar estos dos males. En general, se puede decir que siempre lo logró. El fisiologismo o clientelismo, una expresión más moderada del patrimonialismo, existía en la administración central en el período militar aunque era más la excepción que la regla. Este panorama cambia con la transición democrática. Los dos partidos victoriosos -l PMDB y el PFL- se reparten literal. mente los cargos públicos. La dirección de las empresas estatales, que antes tendía a permanecer en manos de técnicos, se ve también sometida a los intereses políticos dominantes.

15 Estos privilegios, por cieno, no surgieron por causalidad: forman parte de la herencia patrimonialista que Brasil recibió de Portugal. Según Luiz Nassrf (1996): •El análisis de la formación de la economía brasileña muestra que una de las peores plagas de la herencia colonial portuguesa fue el sueño de la seguridad absoluta, que se arraigó profundamente en la cultura social brasileña. En el ámbito de las personas físicas, la manifestación máxima de ese síndrome fue el sueño de la jubilación temprana y el empleo público.

${ }^{16}$ La verdad es que la Constitución sólo exigió que se instituyera el régimen jurídico único. La ley definió que este régimen único sería fijo. En algunos municipios la ley designó como único régimen el régimen celetista. Además, la Constitución, en el art. 19 del ADCT, cuando transforma el puesto de los celetistas con más de cinco años en puesto fijo no los transforma en ocupantes de cargos públicos. Muy al contrario, para poder acceder a cargos públicos han de pasar una ooposición de efectividad. En esta oposición se contaria como título el tiempo trabajado. El STF ha aprobado leyes preliminares que anulan la validez de las leyes de los Estados que tomaron como modeto la ley federal que transformó a celetistas en estatutarios de repente. Sin embargo, hasta el momento nadie ha querido luchar para que se declare inconstitucional la ley 8.112 , un verdadero monumento al corporativismo.

"Según señala PIMEvita (1994: 161): -La función principal de la SAF en el periodo que nos ocupa fue la de garantizar el proceso de fortalecimiento y expansión de la administración directa y defender los intereses corporativistas del funcionalismo, ya fuera influyendo en la elaboración de la nueva Constitución o garantizando la puesta en funcionamiento de lo que se determinó en 1988 .

${ }^{18}$ Acerca del buen hacer profesional y la conciencia pública de la alta burocracia brasileña, ver SCHNEIDER.(1994) y GOUVÉ (1994).

${ }^{19}$ La primera experiencia importante de destitución voluntaria que tuvo éxito dentro del funcionariado brasileño fue la del Banco de Brasi en 1995. El Banco contaba con 130.000 empleados entre los que escogió a 50.000 como posibles sujetos de despido y ofreció una indemnización para que alrededor de 15.000 empleados ofreciese su dimisión. Después de una agitada intervención de los sindicatos, por la que se obruvieron leyes preliminares por parte de jueces de primera instancia, favorables al espíriu burocrático, la política se declaró legal. Se presentaron 16.000 para la destitución voluntaria. En varios estados y en concreto en Río Grande do Sul, programas similares se saldaron con éxito, reduciéndose entre 2 y $4 \%$ el número de funcionarios de los estados. Con el programa federal se redujeron en un $3 \%$.

3) Según PIMIENTA (1994: 154): •Durante todo el período republicano brasileño se va produciendo la institucionalización de la función-administración en el gobiemo federal de forma cíclica ... Brasil pasó por un proceso de centralización organizacional en el sector público en las décadas de los 30 a los 50, en las que se observa un predominio de la administración directa y de los funcionarios fijos. Ya en las décadas de los 60 a los 80 tiene lugar un proceso de descentralización, a través de la generalización de la administración indirecta y de la contratación de funcionarios celetistas (regidos por la CLT). La Constiución de 1988 marca el momento en el que la centralización cobra de nuevo importancia (régimen juridico único-funcionariado fijo).

" La expresión agencia autónoma. quizás sea más adecuada para un órgano que funciona como intermediario entre las agencias ejecutivas y las organizaciones sociales: las agencias reguladoras, que ejercen actividad exclusiva del Estado, pero que deben contar con consejos de dirección con mandato, dotados de mayor autonomía que los de las agencias ejecutivas. Mientras que éstas deben seguir la política definida por el Gobiemo, las agencias reguladoras, al establecer los precios, no deben seguir una política gubernamental que varie con el tiempo y con las circunstancias: su función permanente es establecer el precio que sería el de mercado si existiese tal mercado.

"De acuerdo con lo que señala BANDEIRA DE ME山lo (1975: 14), para el jurista el ser propiedad privada o pública no es meramente un tútulo, significa el sometimiento a un régimen jurídico especifico: un régimen de equilibrio conmutativo entre iguales (régimen privado) o a un régimen de supremacía unilateral, caracterizado por el ejercicio de premogativas especiales de autoridad y de contención propias del ejercicio de tales prerrogativas (régimen público). •Para saber si una actividad es pública o privada simplemente hay que descubrir a qué régimen está sometida. Si el régimen que la ley le atribuye es público, la actividad es pública; si el régimen es de Derecho privado, la actividad se reputará como privada, tanto si es realizada por el Estado, como si no. Resumiendo: no es el sujeto de la actividad, ni su naturaleza lo que le otorga un carácter público o privado, sino el régimen al que, por ley, esté sometida. Reconozco este hecho al observar que la propiedad pública no estatal está regida por el Derecho privado. Es pública desde el punto de vista de sus objetivos, pero privada si se le mira desde el ángulo jurídico.

2. El Derecho Administrativo es la rama del Derecho que organiza e impone disciplina al Estado. Es el Derecho burocrático; de la burocracia. En Brasil, al igual que en los demás paises herederos de las tradiciones jurídicas romana y napoleónica, se trata de una rama del Derecho muy desarrollada.

24 A estas instituciones se les da impropiamente el nombre de organizaciones no gubernamentales. o entidades sin ánimo de lucro, debido a que los politólogos nonteamericanos generalmente confunden gobierno con Estado. Es más correcto hablar de organizaciones no estatales o, expresado de forma más clara, públicas no estatales.

${ }^{3}$ Son o deben ser. porque una entidad formalmente pública, sin ánimo de lucro puede serlo en realidad. En este caso se trata de una entidad pública falsa. Se suelen dar este tipo de casos, especialmente en los ámbitos universitario y hospitalario. 
* Dado que estas instituciones estaban reguladas por el Decreto-ley 200, elaborado por el Estado, después de ta Constitución del 88 , quedaron sometidas a todas las restricciones administrativas impuestas por th administración central.

r. La Cámara de Reforma del Estado está formada por los miniseros de la Administración, de Hacienda, de Planificación, de Trabajo, el Estado Mayor de las Fuerzas Armadas, coordinados por el Jefe de ta Casa Civil de ta Presidencia. $\approx$ Para ser más preciso, asunios como la revisión de la categoría de puesto vitalicio de los funcionarios constaban en las propuestas de reforma constiucional del Gobiemo Collor. Estas ideas fueron producio del trabajo de sectores eruditos de la burocracia preocupados por dotar a aquel gobiemo de un programa mejor esructurado en su segunda fase, después de una profunda restructuración ministerial.

\section{Bibliografia}

ABrucio, Femando L. (1993), PProfesionalización. En Andrade y Jacoud, (org.) (1993).

ANDRADE, R y JACOUD, L. (orgs.) (1993), Estructura y Organización del Poder Ejecutivo-Volumen 2. Brasilia: Escola Nacional de Administraçào Priblica. ENAP.

ANDRADE, Régis (1993), -Introducción. En Andrade y Jacoud, (orgs.) (1993).

asociación Nactonal de especulustas en Polticas Públicas y Gestion Gubervamental (1994), Reforma del Estado y de la Administración Pública: Diagnósticos y Propuestas para el Nuevo Gobierno. Mimeo, octubre de 1994, versión 2.

Bandeira DE Mello, Celso Antônio (1975), Prestación de Senvicios Puiblicos y Administración Indirecta. Revista dos Tribunais, Sào Paulo.

BARZELAY, Michael (1992), Breaking Through Bureaucracy (Penetrar en la Burocracia). Berkeley: University of Califomia Press.

Beltrào, Hélio (1984), Descentralización y Libentad. Río de Janeiro: Record.

BeRTERO, Carlos Osmar (1985), Administración Püblica y Administradores. Brasilia. FUNCEP, 1985.

Bresser Pereira, luiz Carlos (1992), . Contracorriente: la experiencia del Ministerio de Hacienda. Revista Brasileira de Ciencias Sociales, n. ${ }^{\circ} 19$, julio de 1992. Testimonio ante el Instituto Universitario de Investigación de Río de Janeiro (presentado en septiembre de 1988).

_ (1998), ·De Regreso al Capital Mercantil: Caio Prado Jr. y la Crisis de la Nueva República. Revista Brasileña de Ciencias Políticas 1 (1), marzo de 1989. También en María Angela D'Incao, Historia e Ideal: Ensayos sobre Caio Prado Jr. Sào Paulo, Brasiliense, 1989.

Cardoso, Femando Henrique (1996), Globalización. Conferencia pronunciada en Nueva Delhi, India, enero de 1996. Publicada en O Estado de S. Paulo, 28 de enero, 1996.

CavalCavTI DE AlbuQuerQue, Roberto (1995), . La rearticulación de las relaciones Estado-Sociedad: en búsqueda de nuevos sentidos. (en espanol en el original). Revista del Clad-Reforma y Democracia, n. ${ }^{\circ}$, julio de 1995.

DiNIZ, Eli (1995), ·Gobemabilidad, democracia y reforma del Estado: los desafios de la construcción de un nuevo orden en el Brasil de los 90, Dados 38 (3), 1995.

FanRBother, Peter (1994), Politics and the State as Employer (Política y Estado como empleador). Londres: Mansell.

FrISCHTAK, Leila L. (1994), -Govemance Capacity and Economic Reform in Developing Countries. (Gobernabilidad y reforma económica en países en vías de desarrollo). Technical Paper, n. ${ }^{\circ} 254$. World Bank, Washington.

Genro, Tarso (1996), . La izquierda y un nuevo Estado. Folba de S. Paulo, 7 de enero, 1996.

GouvÊ, Gilda Portugal (1994), Burocracia y élites dominantes del País. Sào Paulo: Paulicéia.
GraEF, Aldino (1994), .Nueva fase del capitalismo de Estado. Cadermas ENAP 2 (4), diciembre 1994: Reforma do Estado.

GuRGEl, Cláudio (1995), ·Reforma del Estado: Weber y la Estabilidad. Archétipon 4 (10), 1995 (Río de Janeiro: Facultades Cândido Mendes).

Holavda, Nilson (1993), .la crisis de gestión del Estado brasileño. En Joào Paulo Reis Velloso (org.) (1993), Brasil: la Superación de la Crisis. Sào Paulo: Nobel.

Hunmington, Samuel P. (1968), Political Order in Changing Societies (Orden político en sociedades en proceso de cambio). New Haven: Yale University Press.

IBEP (1997), Los formadores de opinión y la reforma del Estado. Brasilia: IBEP-Insututo Brasileiro de Estudos Políticos, Informe de Investigación, enero de 1997.

KFT, D. and DiluLo, J. (1994), Inside the Reinuention Machine: Appraising Governmental Reform (Dentso de la máquina de reinventar: una valoración de la reforma gubernamental). Washington: The Brookings Institution, Center for Public Management, agosto de 1994.

MARCELNO, Gileno Fernandes (1987), Evolución del Estado y reforma administrativa. Brasilia: Prensa Nacional.

Marnins, Luciano (1973), Pouvoir et Dévéloppement Economique (Poder y desarrollo económico). París: Editions Anthropos, 1976. Tesis de doctorado de estado. Universidad de Paris V, 1873.

_ (1985), Estado capitalista y burocracia en Brasil Pós-64. Rio de Janeiro: Paz e Tema.

Ministerio de la Admistrtración Federal y de la Reforma del Estado (1995), Plan de dirección para la reforma del Estado. Brasilia: Presidencia de la República. Prensa Oficial, noviembre de 1995 .

MINISTERIO DE HACIENDA (1987), Plan de control macroeconómico. Brasilia: Ministerio de Hacienda. Secretaría Especial de Asuntos Económicos, julio de 1987.

NaSSIF, Luiz (19996), •Brasil y el mito de la seguridad. Folba de S. Paulo, 7 de enero, 1996.

NuNES, Edson de Oliveira (1984), Bureaucratic Insulation and Clientelism in Contemporary Brazil. Uneuen State Building and the Taming of Modemity. Ph. D. dissertation. Department of Political Science, University of Berkeley. Traducido como La Gramática Política de Brasil. Río de Janeiro y Brasilia: Zahar Editores y Escola Nacional de Administraçào.

OSBORNE, D. y GAEBLER, T. (1992), Reinventing Government (Reinventar el Gobiemo). Reading, Mass.: Addison-Wesley.

Oslak, Oscar (1995), .Las demandas de formación de administradores públicos frente al nuevo perfil del Estado, Revista do Serviço Prúblico, año 46, vol. 119 , n. ${ }^{\circ} 1$, enero de 1995 .

Pimenta, Carlos César (1994), •Aspectos recientes de la organización y de las politicas de modemización de la función pública federal, Río de Janeiro. Revista de Administración Pública 28 (2), abril de 1994. 
PiQuet Carveiro, Joào Geraldo (1993), -Requisitos políticos y técnicos de la reforma del Estado. En Paulo Reis Velloso, (org.) (1993).

Przeworskl, Adam (1995), .Lo que tienen en común los paises civilizados. Folba de $S$ Paulo, 2 de abril, 1995.

(1995), -Reforming the State: Political Accountability and Economic Intervention. (Reformar el Estado: contabilidad políica e intervención en la economía), Mimeo. Trabajo presentado en la conferencia .Inequality, the Welfare State and Social Values (Desigualdad: el Estado del bienestar y los valores sociales), El Escorial, España, julio de 1995.

(1996), Reforma del Estado: responsabilidad política e intervención económica. Revista Brasileña de Ciencias Sociales 32 (11), octubre de 1996.

Przeworsk, Adam; Bardham, Pranab y Bresser Pererra, luiz Carlos et alli (1995), Sustainable Democracy (Democracia sostenible), Cambridge: Cambridge University Press.
SANTos, Luiz Alberto (1995), Modelo brasileño de organización de la alta Administración, Brasilia: Revista del Servicio Prüblico 119 (2) mayo de 1995.

SCHNEDER, Ben Ross (1994), Burocracia priblica y politica industrial en Brasil. Sào Paulo: Editora Sumaré, 1994.

(1995), La conexión de la profesión: un análisis comparativo de preferencia y aislamiento burocrático. Revista del Servicio Priblico, año 46 , vol. $119, n^{\circ} 1$, enero de 1995.

WEBER, Max (1922), Economy and Society (Economia y Sociedad), Berkeley: University of California Press, 1978. First German Edition, 1922.

(1923), Origen del Estado racional. Chapter 4, Section 8 of Wirtschaftsgescbchte: Abris der Universalen Sozial-und Wirtschafitsgeschichte. Published as an Appendix (pp. 1.047-1.056) to the Spanish translation of Economy and Society, Ciudad de México, Fondo de Cultura Económica, 1964. First German edition, 1923. 